\title{
Blocking autophagy enhances the apoptotic effect of $18 \beta$-glycyrrhetinic acid on human sarcoma cells via endoplasmic reticulum stress and JNK activation
}

\author{
Shuying Shen ${ }^{1}$, Menglu Zhou ${ }^{2}$, Kangmao Huang ${ }^{1}$, Yizheng Wu${ }^{1}$, Yan $\mathrm{Ma}^{1}$, Jiying Wang ${ }^{1}$, Jianjun Ma, ${ }^{\star, 1}$ and Shunwu Fan ${ }^{\star, 1}$
}

Sarcoma, a rare form of cancer, is unlike the much more common carcinomas as it occurs in a distinct type of tissue. The potent antitumor effects of $18 \beta$-glycyrrhetinic acid $(G A)$, a novel naturally derived agent, have been demonstrated in various cancers. However, the effect of GA on human sarcoma, and the underlying mechanisms, remain to be elucidated. In the current study, we show that GA inhibits sarcoma cell proliferation by inducing G0/G1-phase arrest. Exposure to GA resulted in the activation of caspase-3, -8 , and -9 , indicating that GA induced apoptosis through both extrinsic and intrinsic pathways. In addition, the autophagy pathway, characterized by the conversion of LC3-I to LC3- II, was activated, resulting in increased Beclin-1 protein levels, decreased p62 expression, and stimulation of autophagic flux. The present findings showed that GA stimulated autophagy by inducing endoplasmic reticulum (ER) stress via the IRE1-JNK pathway. Our data supported the prosurvival role of GA-induced autophagy when the autophagy pathway was blocked with specific chemical inhibitors. Finally, GA markedly reduced sarcoma growth, with little organ-related toxicity, in vivo. The present results suggest that the combination of GA with a specific autophagy inhibitor represents a promising therapeutic approach for the treatment of sarcoma.

Cell Death and Disease (2017) 8, e3055; doi:10.1038/cddis.2017.441; published online 21 September 2017

There are two general categories of sarcoma: soft-tissue sarcoma, such as fibrosarcoma, and primary bone sarcoma, of which the most common type is osteosarcoma. Both categories are rare, with poor outcome. ${ }^{1}$ Doxorubicin is considered the first-line chemotherapeutic drug for softtissue sarcomas. However, therapeutic doses of doxorubicin have been shown to result in cardiotoxicity. ${ }^{2}$ Osteosarcoma, a highly malignant form of cancer, originates in the osteogenic mesenchymal matrix whose cells are capable of forming osseous, osteoid, cartilaginous, and fibrous tissues. ${ }^{3}$ This form of cancer is well known for its aggression and tendency to form early distant metastases; among these, pulmonary metastasis foci, being the most common, are observed in over $80 \%$ of cases. ${ }^{4,5}$ Current therapeutic strategies against the disease, such as chemotherapy and large-scale surgery, do not significantly increase postsurgical 5-year survival rates. ${ }^{6}$ Therefore, the development of novel treatment approaches and therapeutic drugs for sarcoma is essential.

The 18 $\beta$-glycyrrhetinic acid (GA), the major bioactive component in licorice root, exerts antioxidative, anti-inflammatory, and anticancer effects; ${ }^{7-9}$ in patients with ovarian and breast cancers, the GA-containing Hongdoushan capsule $(\mathrm{CHC})$ has been clinically used as an effective therapeutic strategy. ${ }^{10}$ Furthermore, previous studies have demonstrated that GA suppresses tumor cell growth in breast, ${ }^{8}$ lung, ${ }^{11}$ and gastric $^{12}$ cancers. In addition, GA has been shown to significantly reduce cisplatin-related nephrotoxicity, both in terms of the occurrence rate and severity, via the Nrf2/NF-kB signaling pathway in BALB/c mice. ${ }^{13}$ However, further studies are required to elucidate the mechanisms by which $\mathrm{GA}$ inhibits tumorigenesis in vivo and in vitro.

Cell death may generally be classified as necrosis, autophagy, apoptosis, cornification, and the so-called atypical cell death modalities. ${ }^{14}$ Apoptosis, a type-I programmed cell death (PCD), plays a role in the effect of chemotherapies against various carcinomas. ${ }^{15}$ Autophagy, a type-II PCD, involves the caspase-independent cell death pathway. ${ }^{16}$ In some cellular settings, autophagy may serve as a cell death promoter, working in concert with apoptosis or as a back-up mechanism when the former is defective. However, in others, autophagy serves as a cell survival pathway via the suppression of apoptosis. ${ }^{17}$ It is not known whether GA induces apoptosis or autophagy; furthermore, the specific putative roles of these two forms of cell death and their interplay in GAinduced cell death in cancer remain to be determined.

Autophagy is regulated via the Akt/mammalian target of rapamycin (mTOR) pathway; accordingly, suppression of the Akt/mTOR cascade significantly increases autophagy. Rapamycin, a well-known mTOR inhibitor, is widely used as an inducer of autophagy. ${ }^{18-21}$ The mitogen-activated protein kinase family also act as crucial autophagy mediators. Previous studies have demonstrated that autophagy may be induced by activation of extracellular signal-regulated kinase (ERK) through the action of numerous compounds. ${ }^{22,23}$

\footnotetext{
${ }^{1}$ Department of Orthopaedic Surgery, Sir Run Run Shaw Hospital, Medical College of Zhejiang University, Sir Run Run Shaw Institute of Clinical Medicine of Zhejiang University, 3 East Qingchun Road, Hangzhou, Zhejiang Province, China and ${ }^{2}$ Institute of Biochemistry, College of Life Science, Zhejiang University, Hangzhou, Zhejiang Province, China

*Corresponding author: J Ma or S Fan, Department of Orthopaedic Surgery, Sir Run Run Shaw Hospital, Medical College of Zhejiang University, Sir Run Run Shaw Institute of Clinical Medicine of Zhejiang University, 3 East Qingchun Road, Hangzhou, Zhejiang Province 310016, China. Tel: +86 571 86006667; Fax: +86 571 86044817; E-mail: sealteam@zju.edu.cn or $0099203 @$ zju.edu.cn

Received 03.5.17; revised 30.7.17; accepted 01.8.17; Edited by B Zhivotovsky
} 
Recent electron tomography analyses have demonstrated that autophagosome membranes are connected to the ER, thereby suggesting a direct connection between the ER and autophagy. ${ }^{24,25} \mathrm{C}$-Jun $\mathrm{N}$-terminal kinase (JNK) further exerts important effects on endoplasmic reticulum (ER) stressinduced autophagy; in JNK pathway-deficient in vitro and in vivo models, ER stress-induced cell death is significantly elevated in the absence of autophagy. ${ }^{26,27}$

In the present study, we demonstrated the inhibitory effect of GA on sarcoma cell lines in vitro and in vivo, and explored the underlying molecular mechanisms by which GA elicits these effects. We additionally confirmed that GA induces cytoprotective autophagy in sarcoma cells via IRE1a-JNK/c-jun cascade activation, and that inhibition of autophagy or the JNK pathway increases GA-induced inhibitory effects and apoptosis on sarcoma cells.

\section{Results}

GA inhibits the proliferation of sarcoma and induces G0/G1-phase arrest by regulating cell cycle-regulated proteins. In order to investigate the effect of GA on cell growth, HOS and HT1080 cells were exposed to GA at various concentrations for 24,48 , and $72 \mathrm{~h}$ (Figure 1a). The $I_{50}$ values were $45.845 \mu \mathrm{M}(24 \mathrm{~h}), 34.81 \mu \mathrm{M}(48 \mathrm{~h})$, and $24.436 \mu \mathrm{M}(72 \mathrm{~h})$ for HOS cells; $I_{50}$ values were $34.013 \mu \mathrm{M}(24 \mathrm{~h}), 25.656 \mu \mathrm{M}(48 \mathrm{~h})$, and $20.554 \mu \mathrm{M}$ (72 h) for HT1080 cells. Colony formation assays showed that fewer colonies were formed following GA treatment (Figure 1b). These results demonstrated that GA inhibits proliferation of sarcoma in a dose- and time-dependent manner. Cell migration is essential for sarcoma cells in metastasis. Therefore, we performed transwell assays to evaluate the ability of sarcoma cells to pass through the membrane barriers of the transwell in the presence of various concentrations of GA. As shown in Figure 1c, GA significantly inhibited the migratory activities of sarcoma cells in a concentration-dependent manner.

In order to determine whether GA inhibits cell proliferation via induction of cell cycle arrest, we examined cell cycle stages in cells treated with GA. As shown in Figure 1d, GA treatment in HOS and HT1080 cells resulted in an accumulation of cells in G0/G1 phase, and a corresponding decrease in cells in $\mathrm{G} 2 / \mathrm{M}$ and $\mathrm{S}$ phases. To elucidate the mechanisms underlying this phenomenon, we measured protein expression cell cycle regulators. Results indicated that GA downregulates the expression of Cyclin E, CDK4, and Cyclin D1 (Figure 1e), but has no effect on their mRNA levels (Supplementary Figure S1). These results clearly indicated that GA induces G0/G1-phase arrest by altering the expression of G0/G1 cell cycle regulators.

GA induces apoptosis of sarcoma cells. In order to determine whether apoptosis is responsible for the inhibition of cell growth in response to GA, we further explored the effects of GA on apoptosis and cell death in HOS cells. Hoechst 33342 staining was used to estimate GA-dependent changes in cell morphology. Results indicated that GA treatment for $24 \mathrm{~h}$ induced cell shrinkage, chromatin condensation, and nuclear fragmentation (Figure 2a). Flow cytometric analysis using annexin V- FITC/PI staining was performed. The apoptosis rate of untreated cells was negligible; however, $24 \mathrm{~h}$ following GA exposure in sarcoma cells, we observed a dose-dependent increase in both early and late apoptotic cells (Figure 2b). Next, in order to confirm the involvement of mitochondria GA-associated cell apoptosis, the fluorescent mitochondrial probe JC-1 was used to measure the mitochondrial membrane potential (MMP). As shown in Figure 2c and Supplementary Figure S1, MMP was sharply reduced following GA treatment, suggesting that mitochondrial depolarization was induced by exposure to GA in sarcoma cells.

GA induces caspase-dependent apoptosis through the intrinsic pathways. In mammalian cells, apoptosis may be induced by extra- or intracellular stimuli, triggering the extrinsic (via cell-surface death receptors) or intrinsic pathways (via mitochondrial signaling), respectively. ${ }^{28}$ In order to determine whether GA-induced apoptosis is mediated by extrinsic or intrinsic pathways, we investigated the expression of downstream apoptotic proteins by western blot. Caspase-8 and -9 act as initiator caspases in the extrinsic and intrinsic (mitochondrial) apoptosis pathways, respectively. As shown in Figure $2 \mathrm{~d}$, a significance increase in activation of cleavage caspase-3, -8, and -9 , as well as of PARP, was observed. However, the expression of $\mathrm{Bcl}-2, \mathrm{Bcl}-\mathrm{xl}$, and survivin was reduced. Taken together, these data indicated that GA induces cell apoptosis via activation of both the extrinsic and intrinsic pathways. In order to confirm these results, we performed caspase activity assays. Activities of caspase-3, -8, and -9 increased with escalating doses of GA (Figure 2e). We further investigated the roles of these caspases using z-VAD-fmk, z-IETD-fmk, and z-LEHD-fmk. As expected, we observed a moderate inhibitory effect for z-IETD-fmk and z-LEHD-fmk in GA-induced apoptosis; z-VAD-fmk demonstrated a more potent inhibitory effect (Figure 2f). These data confirmed that GA stimulates caspase-dependent apoptosis via activation both extrinsic and intrinsic pathways.

GA triggers autophagy in sarcoma cells. The occurrence of autophagy in GA-treated HOS and HT1080 cells was investigated by measurement of LC3-I to LC3-II conversion, a hallmark of autophagy. In addition, protein levels of Beclin-1, a key regulator of autophagy formation, ${ }^{29}$ as well as p62, a selective target of autophagy, was measured. As shown in Figures $3 a$ and $b$, protein levels of Beclin- 1 were elevated following GA treatment; furthermore, conversion of LC3-I to LC3-II was significantly enhanced. The expression of the autophagy-related protein 5 (Atg5) also exhibited continuous increase following treatment with GA. Previous studies have shown that $\mathrm{p} 62$ is degraded during the autophagy process; ${ }^{14}$ here, p62 levels were significantly reduced after $24 \mathrm{~h}$ of treatment with GA. Furthermore, GA treatment led to the accumulation of bright red acidic vesicles resembling autolysosomes (Figure 3c). To confirm occurrence of autophagy, we measured the incorporation of MDC, a marker for mature autophagic vacuoles (AVs) such as autophagolysosomes, in sarcoma cells. GA treatment significantly increased the level 
a
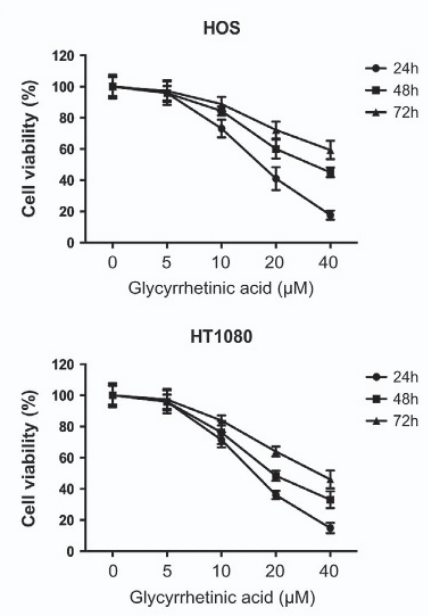

d
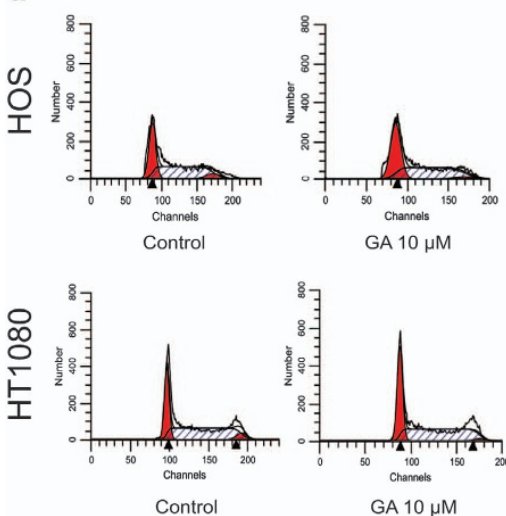

b

нов

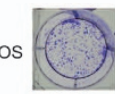

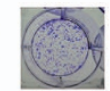

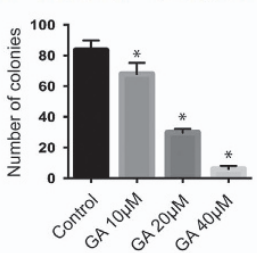

HT1080

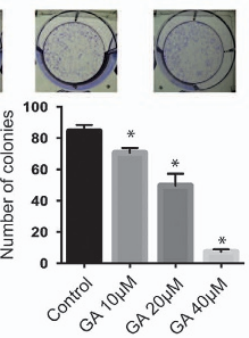

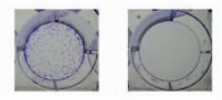
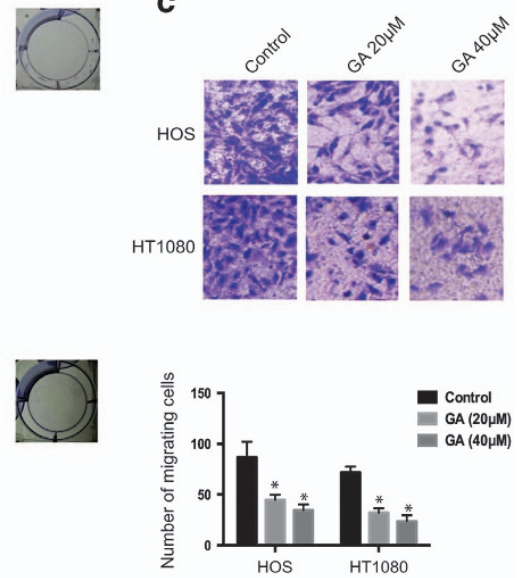
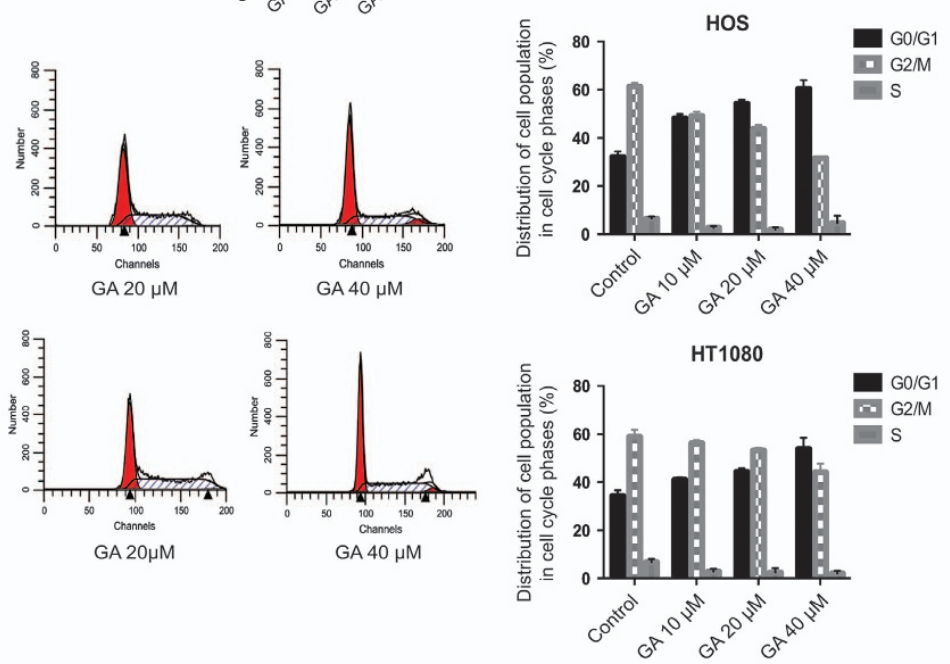

e HOS

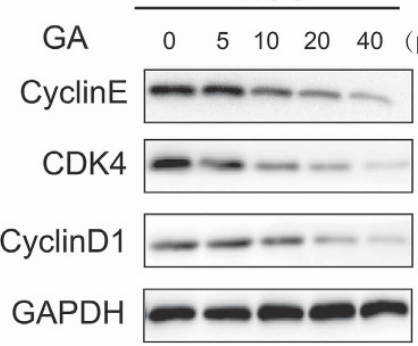

$(\mu \mathrm{M})$

$56 \mathrm{kDa}$

GA

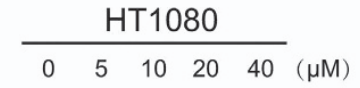

CyclinE

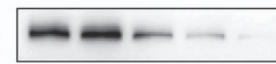

$56 \mathrm{kDa}$

$34 \mathrm{kDa}$

CDK4

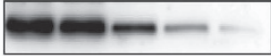

$34 \mathrm{kDa}$

$36 \mathrm{kDa}$ CyclinD1

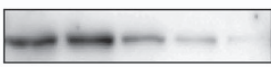

$36 \mathrm{kDa}$

$37 \mathrm{kDa}$

GAPDH

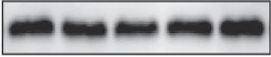

$37 \mathrm{kDa}$

Figure 1 Cytotoxic effects and G0/G1-phase arrest resulting from GA treatment in sarcoma cells. (a) The antiproliferative effect of GA on sarcoma cell lines was determined by MTT. Cells were treated with various concentrations of GA for 24,48 , and $72 \mathrm{~h}$. Control group contained $0.1 \%$ DMSO. Data represented the mean of five replicates. Each experiment was performed in triplicate. (b) Colony formation assay of HOS and HT1080 cells with control or GA. Cells were treated with GA at varying concentrations for $\sim 14$ days when the cells grew to visible colonies. (c) GA inhibited sarcoma cell invasion in transwell assay. The bottom chambers of the transwells were filled with $600 \mu$ l DMEM containing various growth factors, whereas the top chambers were seeded with $4 \times 10^{4}$ sarcoma cells in DMEM and treated with different concentrations of GA for $24 \mathrm{~h}$. Cells that migrated through the membrane were stained. Number of migrating cells was counted. ${ }^{*} P<0.05$, significantly different compared with control. (d) GA induced G0/G1-phase arrest. Cells were treated with control or GA for $24 \mathrm{~h}$ and analyzed by flow cytometry. The percentage of cell cycle distribution was presented as the mean \pm S.D. from three independent experiments. (e) HOS and HT1080 cells were treated with GA for $24 \mathrm{~h}$. The expressions of cell cycle-regulated proteins were measured by western blot. ${ }^{*} P<0.05$, significantly different compared with control

of MDC-stained AVs in both sarcoma cell types used (Figure 3d). Transmission electron microscopy (TEM) was used to directly observe autophagosome formation. As shown in Figure $3 e$, we observed numerous large autophagic vacuoles in the cytoplasm with degraded vacuolar contents, concurrent with apoptotic chromatin condensation. These results provided evidence for a role of GA in regulation of autophagosome formation in sarcoma cells. 
a

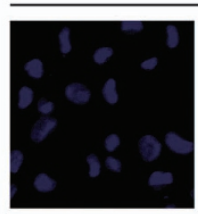

Control
HOS

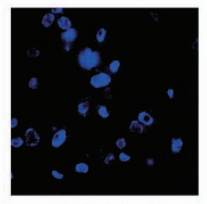

GA $40 \mu \mathrm{M}$

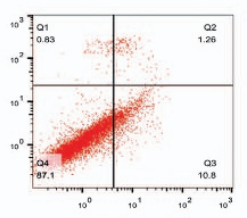

GA $10 \mu \mathrm{M}$

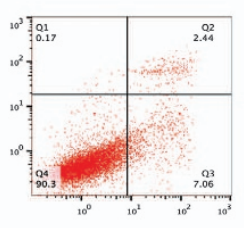

GA $10 \mu \mathrm{M}$

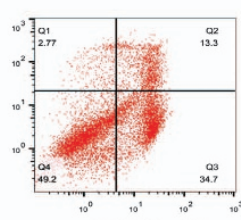

$\mathrm{GA} 20 \mu \mathrm{M}$

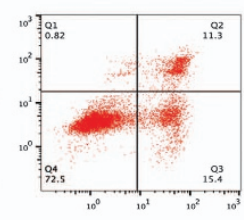

GA $20 \mu \mathrm{M}$

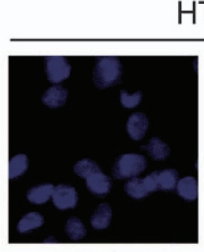

Control
HT1080

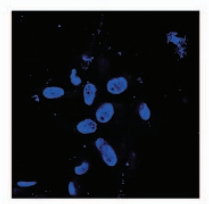

GA $40 \mu \mathrm{M}$

b

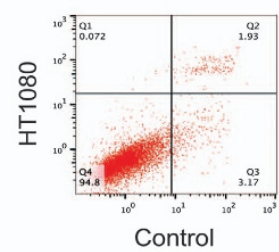

d

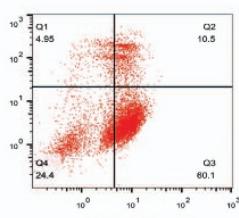

$\mathrm{GA} 40 \mu \mathrm{M}$

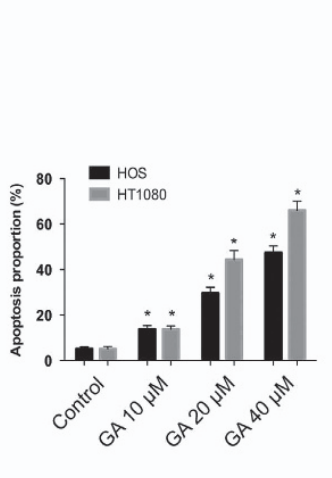

HOS

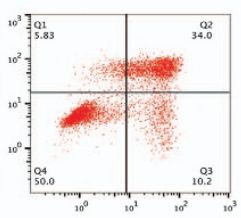

GA $40 \mu \mathrm{M}$
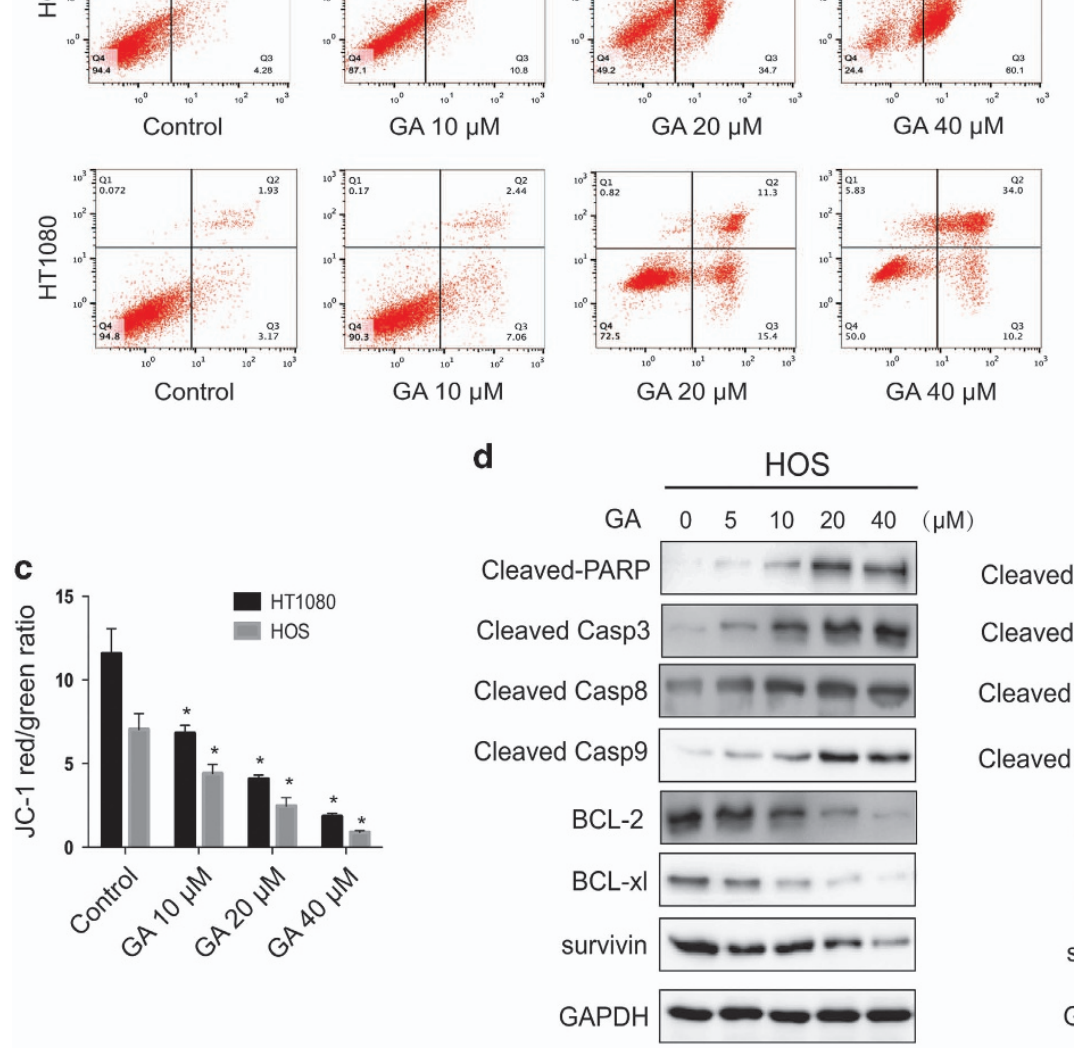

$\mu \mathrm{M})$

HT1080

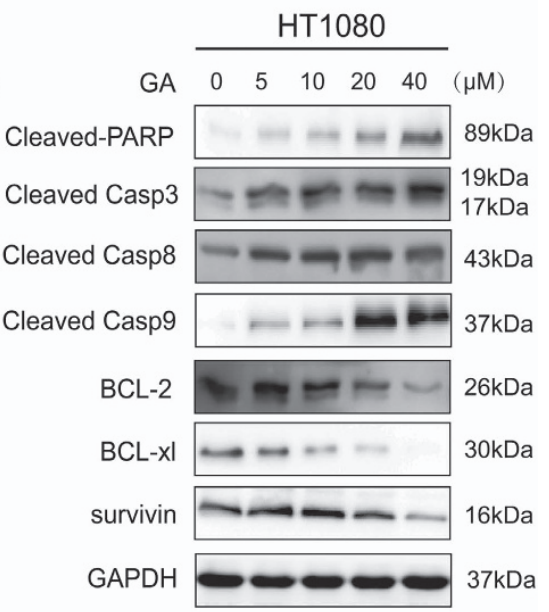

e
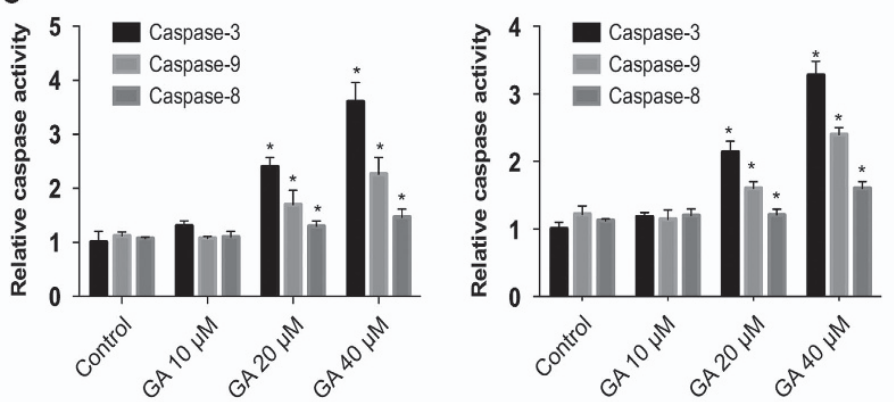

f

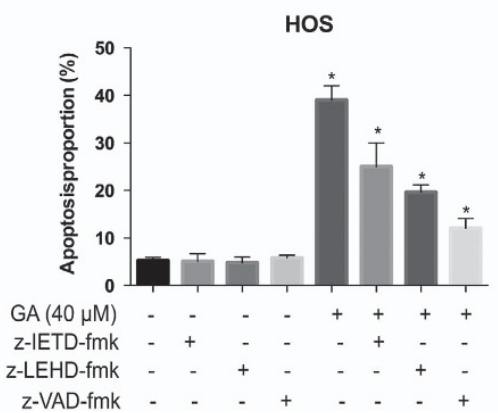

Figure 2 Evidence that GA induces apoptosis in sarcoma cells. (a) Apoptotic morphological changes were evaluated by fluorescent microscopy using Hoechst 33342 staining. Arrows indicate chromatin condensation and DNA fragmentation. Bar, $50 \mu \mathrm{m}$. (b) HOS and HT1080 cells treated with GA were stained with annexin V-FITC/PI and analyzed by flow cytometry. The chart illustrates apoptosis proportion from three separate experiments. (c) The mitochondrial membrane potential was measured with JC-1 fluorescent probe and assessed by flow cytometry. The chart illustrates changes of JC-1 red/green rate from three independent experiments. (d and e) Cells were treated with various concentrations of GA for $24 \mathrm{~h}$. The expressions of cleaved PARP, caspase- $3,-8,-9, \mathrm{BCL}-2, \mathrm{BCL}-\mathrm{XL}$, and survivin were determined by western blot. (e) Caspase activity assay of cells treated with various concentrations of GA for $24 \mathrm{~h}$. (f) HOS cells were incubated with or without GA for $24 \mathrm{~h}$ after $2 \mathrm{~h}$ of pretreatment with caspase inhibitors, z-IETDfmk $(10 \mu \mathrm{M})$, z-LEHD-fmk $(40 \mu \mathrm{M})$, or z-VAD-fmk $(20 \mu \mathrm{M})$. Then, cells were stained with annexin V-FITC/PI and analyzed by flow cytometry. Results are expressed as the mean \pm S.D. from three independent experiments. ${ }^{*} P<0.05$ versus control, ${ }^{\#} \mathrm{P}<0.05$ versus GA treatment 

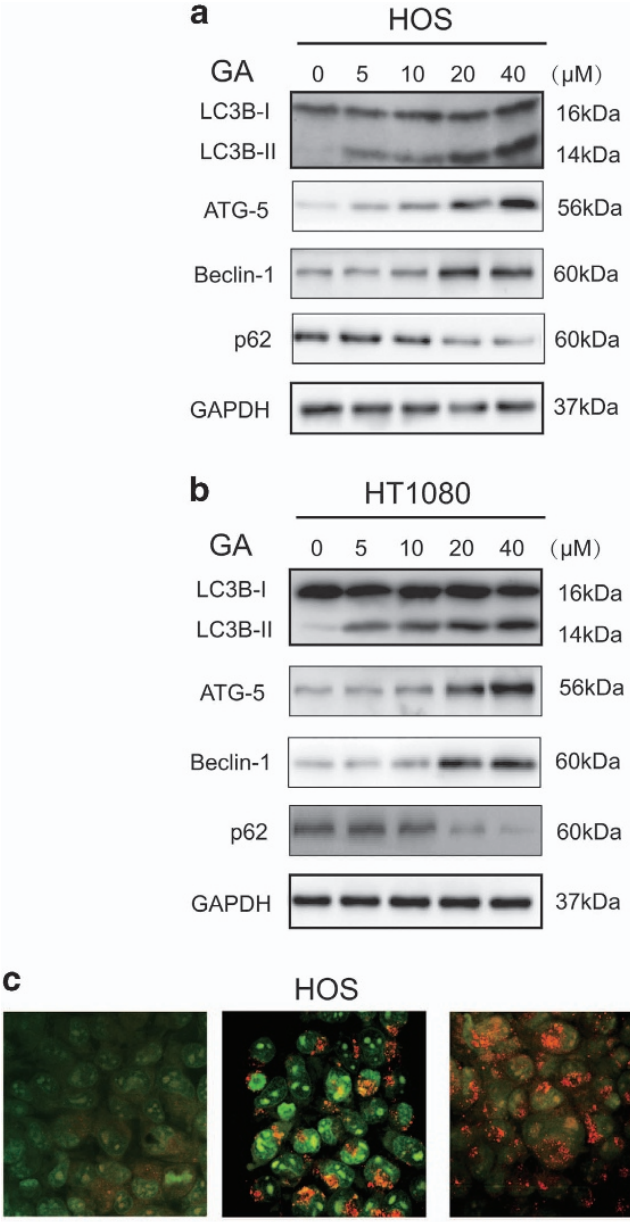

Control

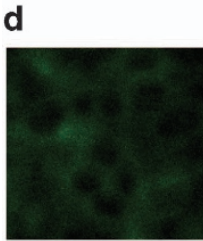

Control

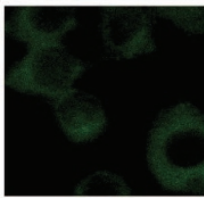

Control
HOS

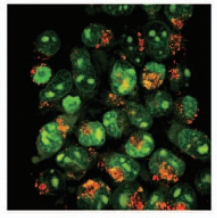

$\mathrm{GA}(20 \mu \mathrm{M})$

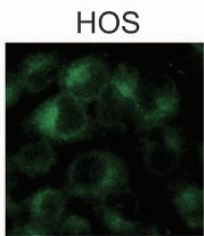

$\mathrm{GA}(20 \mu \mathrm{M})$

HT1080

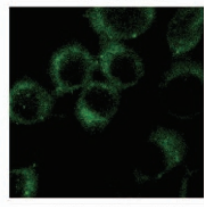

$\mathrm{GA}(20 \mu \mathrm{M})$

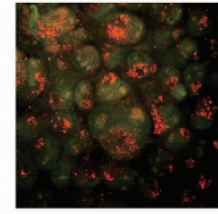

$\mathrm{GA}(40 \mu \mathrm{M})$

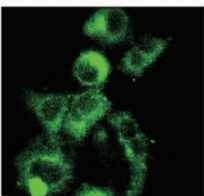

$\mathrm{GA}(40 \mu \mathrm{M})$

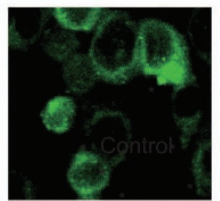

$\mathrm{GA}(40 \mu \mathrm{M})$
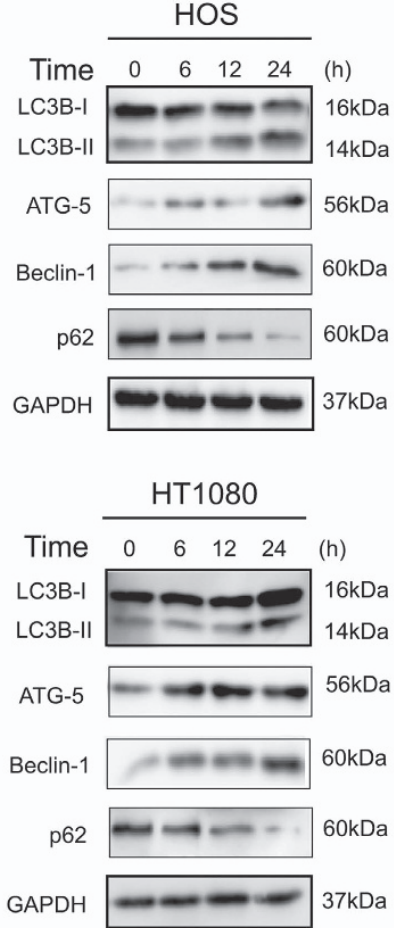

HT1080

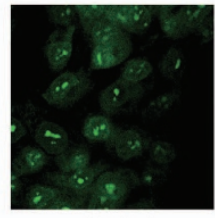

Control

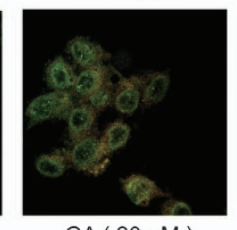

$\mathrm{GA}(20 \mu \mathrm{M})$

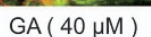

e

HOS
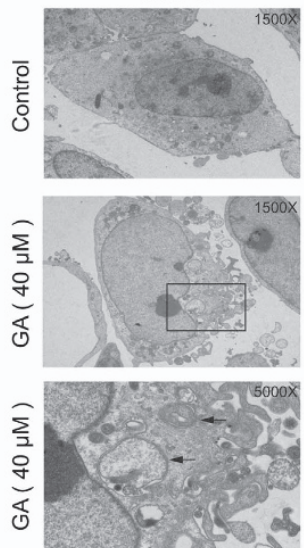

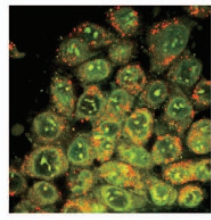

$\mathrm{GA}(40 \mu \mathrm{M})$

Figure 3 GA induces autophagy. (a and $\mathbf{b}$ ) Cells were treated with various concentrations of GA for 24 h or incubated with $\mathrm{GA}$ (40 $\mu \mathrm{M}$ ) for different hours. The level of LC3B, Atg5, Beclin-1, and p62 was measured by western blot. (c) Cells treated with or without GA for $24 \mathrm{~h}$ were collected and stained with acridine orange. Representative images of acridine orange-stained cells captured by fluorescent microscopy $(\times 400)$ are shown. Bar, $50 \mu \mathrm{m}$. (d) Sarcoma cells were treated with GA for $24 \mathrm{~h}$ and stained by MDC. (e) Transmission electron microscopy was utilized to observe the formation of autophagosome and ultrastructural change of nucleus. Arrows indicate autophagosomes containing intact and degraded cellular debris. Asterisks indicate nuclear condensation. Bar, $1 \mu \mathrm{m}$

GA induces autophagy via JNK/c-jun pathway activation in sarcoma cells. The JNK/c-jun pathway plays a pivotal role in autophagy, and activation of $\mathrm{JNK} / \mathrm{c}$-jun induces autophagy under diverse conditions. ${ }^{30,31}$ Therefore, we investigated whether GA was capable of inducing autophagy via the JNK/ c-jun cascade. As shown in Figure 4a, GA induced phosphorylation of JNK and c-Jun in a concentration-dependent manner in both HOS and HT1080 cells. 
a

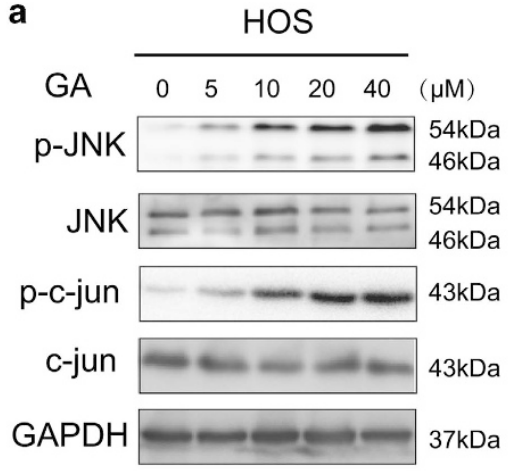

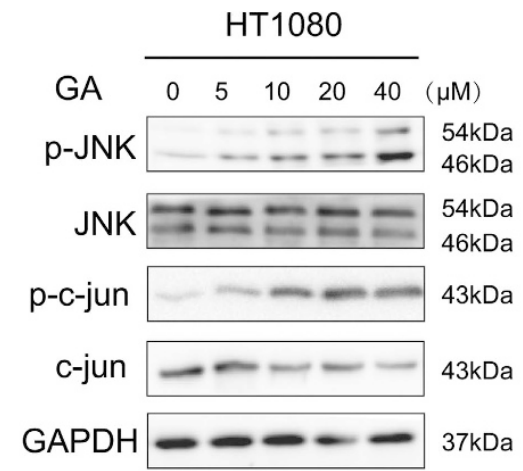

c

b

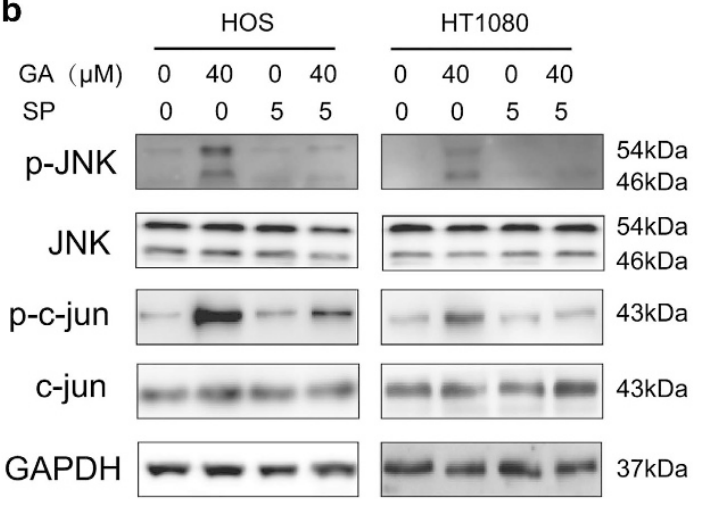

d

HOS

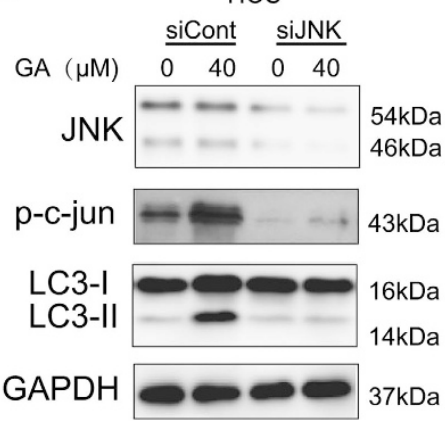

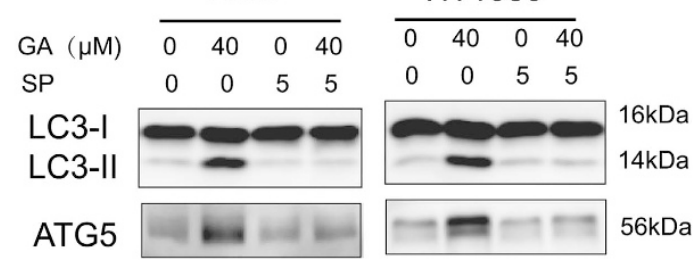

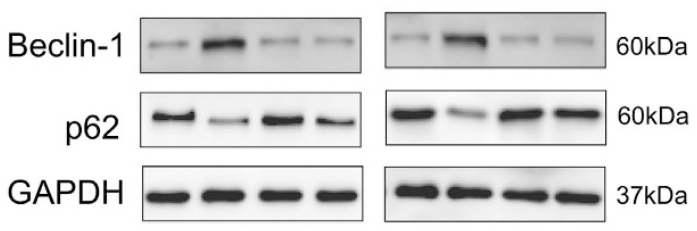

HT1080

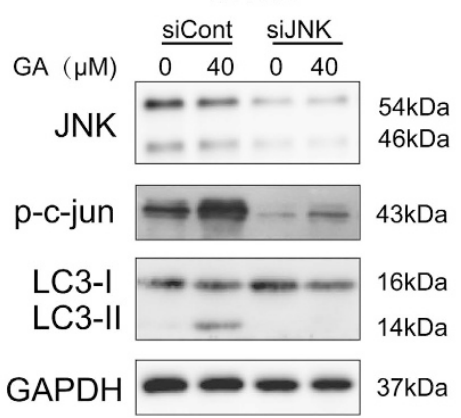

Figure 4 GA activates autophagy through JNK/c-jun signal pathway. (a) Cells were treated with various concentrations of GA for $24 \mathrm{~h}$. The expression of p-JNK, JNK, p-cJun, and Jun were analyzed by western blotting. (b) Sarcoma cells was preincubated with SP600125 (30 $\mu \mathrm{M})$ for $2 \mathrm{~h}$ and then treated with GA for $24 \mathrm{~h}$. Levels of p-JNK, JNK, p-cjun, and c-jun were analyzed by western blotting. (c) Sarcoma cells was preincubated with SP600125 (30 $\mu \mathrm{M})$ for $2 \mathrm{~h}$ and then treated with GA for $24 \mathrm{~h}$. Levels of Atg5, Beclin-1, and p62 were analyzed by western blotting. (d) After knockdown of JNK by siRNA, HOS and HT1080 cells were incubated in GA (40 $\mu \mathrm{M})$ for $24 \mathrm{~h}$. Levels of JNK, p-c-Jun, and LC3-I/II were analyzed by western blotting

The JNK/c-jun pathway inhibitor SP600125 was used to determine whether GA induces autophagy via JNK/c-jun activation. ${ }^{32}$ As shown in Figure $4 \mathrm{~b}, \mathrm{GA}$-activated JNK and c-jun levels were decreased following pretreatment with SP600125 $(10 \mu \mathrm{M}, 1 \mathrm{~h})$. In addition, induction of autophagy markers such as LC3-II, ATG5, and Beclin-1 was also reversed following SP600125 treatment. This further suggested that GA induces autophagy via the JNK/C-jun pathway (Figure 4c). In order to confirm the role of JNK in GA-induced autophagy, JNK silencing was performed using siRNA. We observed a decrease in GA-induced LC3-II expression in both HOS and HT1080 cell lines (Figure 4d) following JNK inhibition. Therefore, activation of the $\mathrm{JNK} / \mathrm{c}$-jun cascade is pivotal for GA-induced autophagy in sarcoma cells.

ER stress-stimulated JNK/c-jun activation is critical for GA-induced autophagy in sarcoma cells. Two classic ER stress inducers, thapsigargin and tunicamycin, have been found to stimulate autophagy. ${ }^{27,33}$ In the current study, we found that GA-induced activation of JNK/c-jun activation was mediated by ER stress. Expression of the ER stress sensor IRE1a, as well as its downstream molecule XBP-1s, and the ER stress-related proteins Chop and Bip were increased after GA treatment (Figure 5a). IRE1a knockdown by siRNA 
a

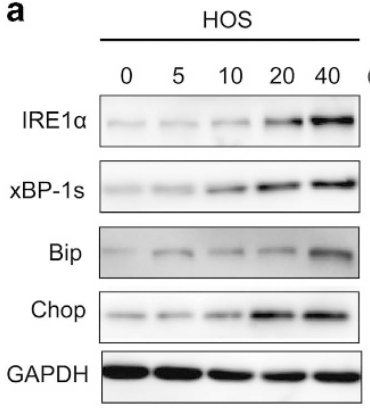

$(\mu \mathrm{M})$ $110 \mathrm{kDa}$

$29 \mathrm{kDa}$

$78 \mathrm{kDa}$

$27 \mathrm{kDa}$

$37 \mathrm{kDa}$

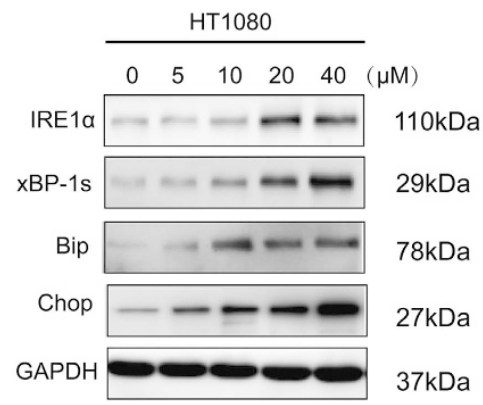

b

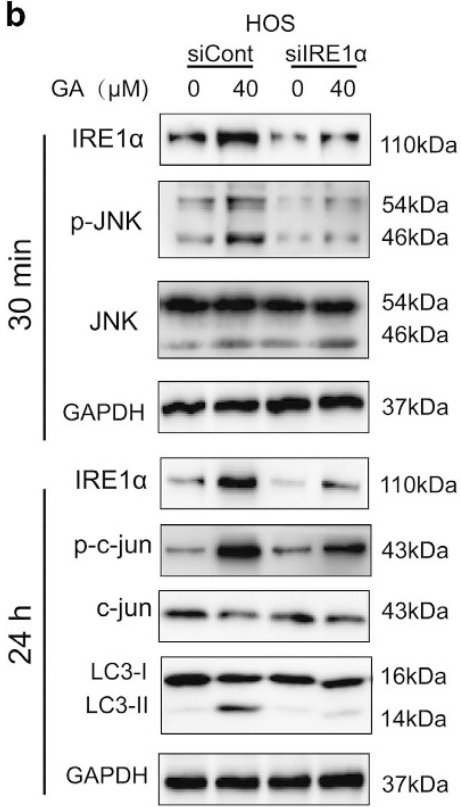

C

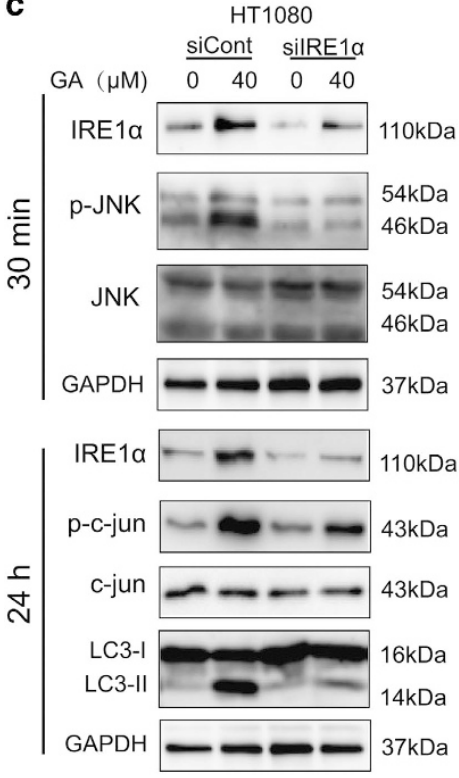

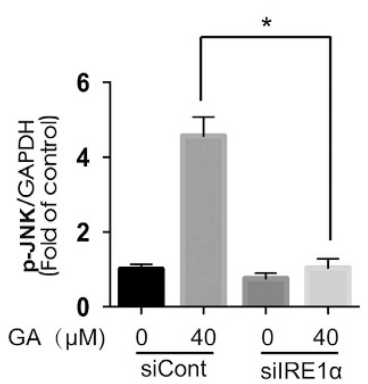
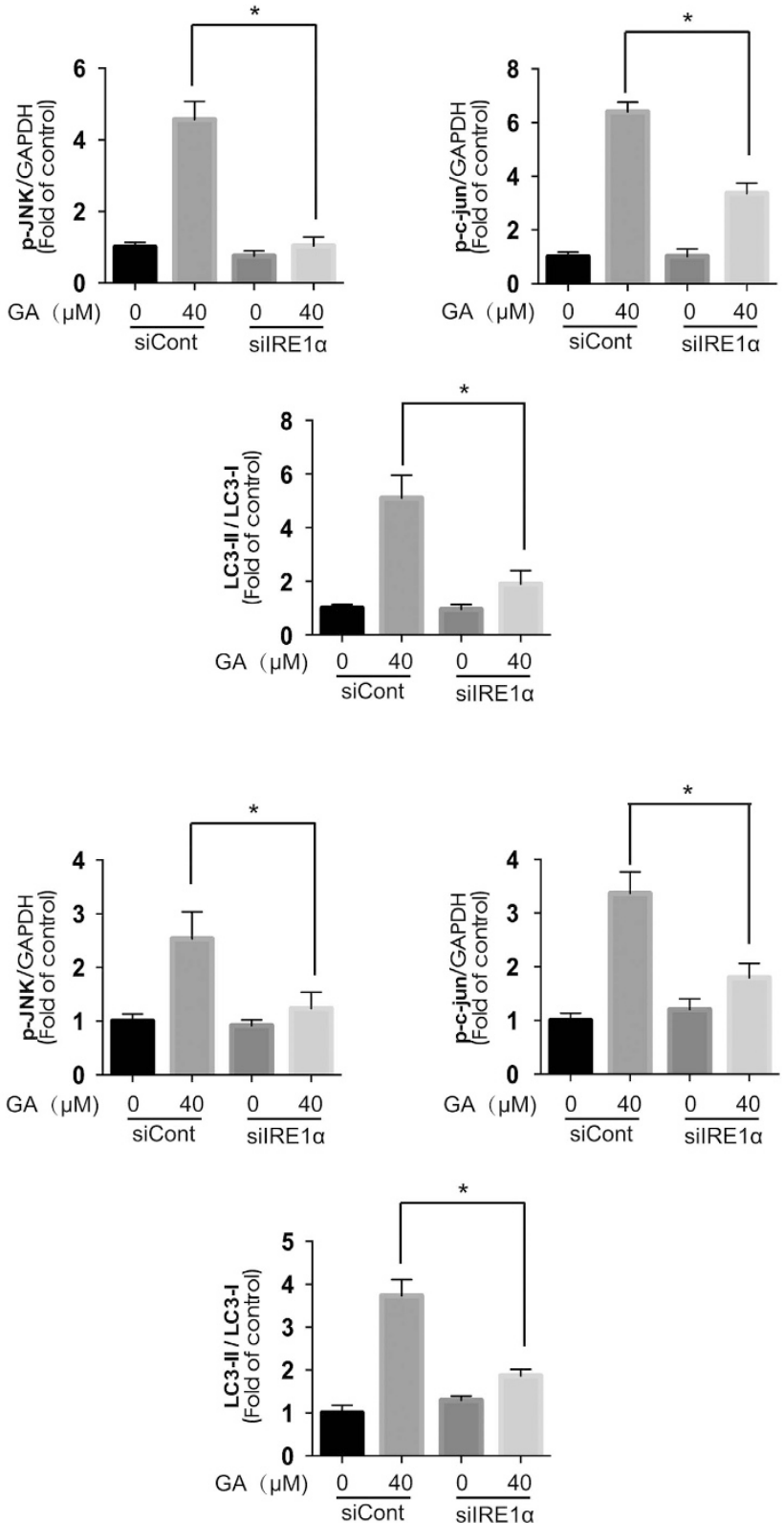

Figure 5 The IRE1 $\alpha$-JNK/c-jun pathway is essential for GA-induced autophagy in sarcoma cells. (a) HOS and HT1080 cells were treated with varying concentrations of GA for $24 \mathrm{~h}$, and the ER stress-related protein expression was evaluated by western blot analysis. (b and c) HOS and HT1080 cells were infected with scramble or IRE $1 \alpha$ siRNA and then incubated for $24 \mathrm{~h}$. GA $(40 \mu \mathrm{M})$ was added to the cells for $30 \mathrm{~min}$ or $24 \mathrm{~h}$. Protein expression related to the JNK/c-jun pathway and autophagy was detected by western blot analysis. ${ }^{*} P<0.05$ 
a

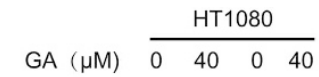

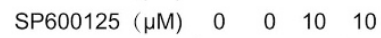

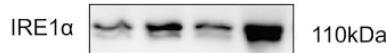
$\mathrm{GAPDH}=37 \mathrm{kDa}$

b

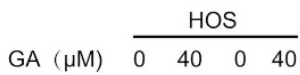
$\mathrm{SP} 600125(\mu \mathrm{M}) \quad 0 \quad 0 \quad 10 \quad 10$

IRE1a $--\infty 110 \mathrm{kDa}$

$\mathrm{GAPDH}=-2 \mathrm{~m}-\boldsymbol{\mathrm { kDa }}$

C

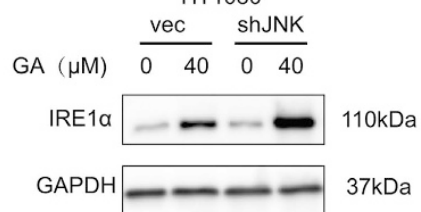

d

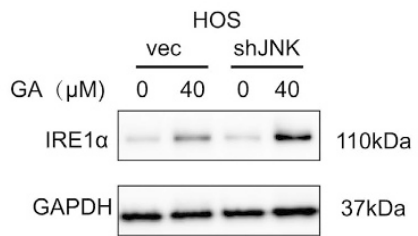

e

\begin{tabular}{lllll} 
& \multicolumn{3}{l}{$\mathrm{HT} 1080$} \\
\cline { 2 - 5 } $\mathrm{GA}(\mu \mathrm{M})$ & 0 & 40 & 0 & 40
\end{tabular}

$\mathrm{CQ}(\mu \mathrm{M}) \quad 0 \quad 0 \quad 5 \quad 5$

IRE1 $=--\infty 110 \mathrm{kDa}$

GAPDH $=-37 \mathrm{kDa}$

f

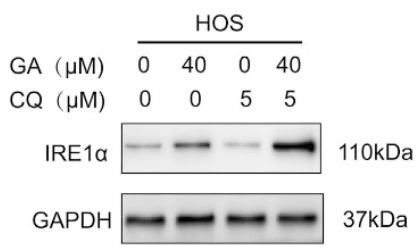

g

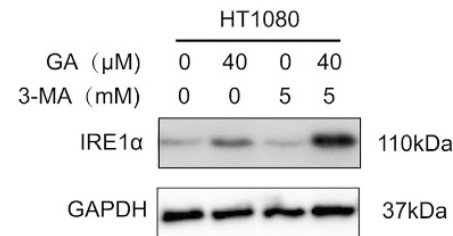

h

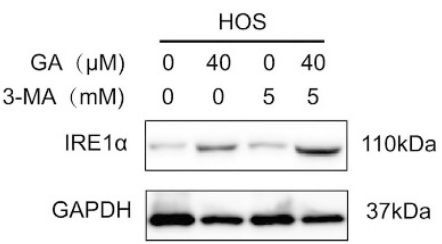

HT1080
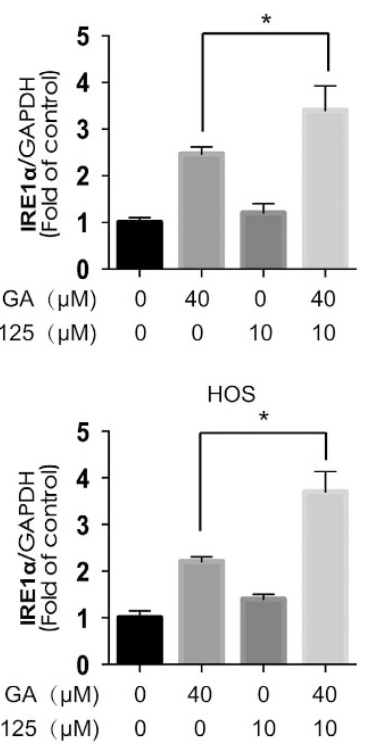

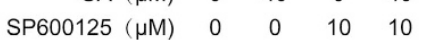
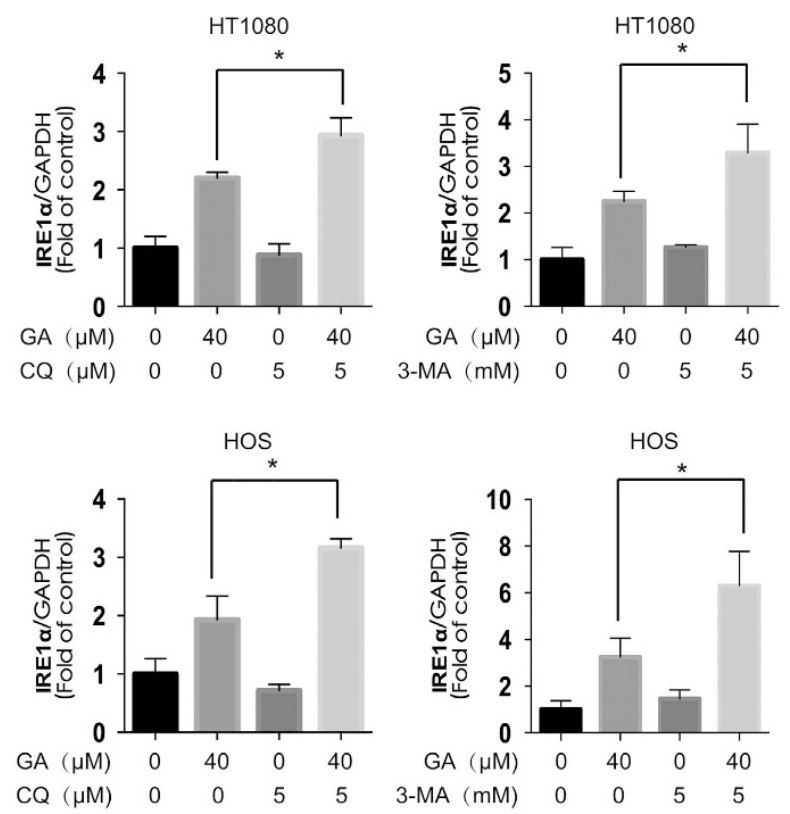
Figure 6 Inhibition of JNK/C-jun and autophagy increases GA-induced ER stress in sarcoma cells. (a and b) After suppression of the JNK/c-jun cascade by SP600125 $(10 \mu \mathrm{M}, 1 \mathrm{~h})$ pretreatment, HT1080 and HOS cells were treated with $\mathrm{GA}(40 \mu \mathrm{M})$ for $24 \mathrm{~h}$. Protein expression levels were detected by western blot analysis. ${ }^{\star} P<0.05$. (c and d) After suppression of the JNK by shRNA transfection, HT1080 and HOS cells were treated with GA (40 $\mu \mathrm{M})$ for $24 \mathrm{~h}$. Protein expression levels were detected by western blot analysis. ${ }^{*} P<0.05$. (e and f) HT1080 and HOS cells were treated with GA (40 $\left.\mu \mathrm{M}\right)$ for $24 \mathrm{~h}$ with or without pretreatment of $\mathrm{CQ}(5 \mu \mathrm{M}, 1 \mathrm{~h})$. Western blot analysis was used to examine protein expression. ${ }^{*} P<0.05$. ( $g$ and $\mathbf{h}$ ) HT1080 and HOS cells were treated with $\mathrm{GA}(40 \mu \mathrm{M})$ for $24 \mathrm{~h}$ with or without pretreatment of $3-\mathrm{MA}$ ( 5 mM, $2 \mathrm{~h}$ ). Western blot analysis was used to examine protein expression. ${ }^{*} P<0.05$

decreased GA-induced autophagy, as evidenced by decreased LC3-II expression (Figures 5b and c). In addition, ER stress and JNK/C-jun was found to be correlated in HOS and HT1080 cells. Knockdown of IRE1a partly inhibited phosphorylation of JNK and c-jun after $30 \mathrm{~min}$ and $24 \mathrm{~h}$ of GA treatment, respectively (Figures $5 \mathrm{~b}$ and c, Supplementary Figure S3). However, JNK knockdown, as well as inhibition of the JNK/c-jun pathway by SP600125, increased GA-induced ER stress in HOS and HT1080 cells (Figures 6a-d, Supplementary Figure S4) that may be attributed to inhibition of GA-induced autophagy. Combined treatment with GA and $\mathrm{CQ}$ or 3-MA also increased GA-induced ER stress (Figures $6 \mathrm{e}-\mathrm{h}$ ), suggesting that inhibition of autophagy results in increased levels of misfolded and damaged proteins in the cell that initiates the ER stress response. ${ }^{27}$ These results indicated that GA induces autophagy in HOS and HT1080 cells via the IRE $1 a-J N K / c-j u n$ pathway, and that inhibition of JNK/c-jun or autophagy increases GA-induced ER stress.

Protective autophagy during GA treatment. It is known that autophagy can serve either as an alternative form of programmed cell death or a form of protection during critical periods. ${ }^{34}$ To determine whether autophagy induced by ER stress promotes cell survival or cell death in sarcoma cells, we used specific inhibitors of autophagy. Cells were treated with bafilomycin A1 that inhibits fusion of the autophagosome with the lysosome; we also examined the effect of 3methyladenine (3-MA) that suppresses the activity of the class III PI3Ks. Sarcoma cells were pretreated with $10 \mathrm{mM}$ 3-MA or $100 \mathrm{nM}$ bafilomycin A1 for $6 \mathrm{~h}$; neither agents exerted significant toxic effects on cells. The inhibitory effect of these drugs on autophagy was assessed using MTT and annexin V/PI staining. As compared with untreated cells, bafilomycin A1- or 3-MA-treated cells underwent extensive cell death after GA treatment (Figures $7 b$ and $c$ ). In addition, Atg5 siRNA-transfected cells also exhibited significantly increased cell death and apoptosis rates in response to GA (Figures 7 e and f). As the IRE1a-JNK/c-jun pathway plays an important role in GA-induced autophagy, we evaluated the effect of GA on cell growth and apoptosis via suppression of the JNK/c-jun pathway. As expected, GA inhibited cell growth inhibition, and an increase in apoptosis was found following JNK blockage in both HOS and HT1080 sarcoma cell lines (Figures 7d-f). Furthermore, both autophagy inhibition and JNK knockdown enhanced the level of apoptosis-related proteins following GA treatment (Figures $7 a$ and d). These data suggested that ER stress-induced autophagy mediated by GA treatment exerts cytoprotective effects.

GA inhibits growth of osteosarcoma in vivo. In order to examine the antitumor effect of GA in vivo, an orthotopic OS model was established by intratibial injection of HOS cells into mice. Mice in the experimental group were injected with GA (2 mg/kg), whereas those in the control group received $5 \%$ dimethyl sulfoxide (DMSO) intraperitoneally every other day (seven times in total). As shown in Figures $8 a$ and b, GA inhibited tumor growth. However, no significant decrease in body weight was observed in experimental mice (Figure 8c). Moreover, GA-treated tumor tissues showed significant increase in TUNEL-positive cells, and exhibited increased levels of cleaved caspase-3 and JNK phosphorylation (Figure 8d). As shown in Figure 8e, GA treatment led to elevated levels of cleaved caspase-3, LC3B-II, phospho-JNK, Cyclin E, CDK4, and Cyclin D1. In order to investigate the potential cytotoxic effects of GA on normal tissues, nontumorbearing mice were intraperitoneally treated with GA; hematoxylin and eosin (H\&E) staining of organs collected at the end of the experiment revealed no major organ-related toxicities (Figure 8f). These data suggested that GA exhibits potent antitumor activity with low toxicity in vivo.

\section{Discussion}

Triterpene saponin GA, the primary ingredient of numerous traditional Chinese medicines for cancer, ${ }^{35,36}$ is the main bioactive and metabolic component in vivo. ${ }^{37,38}$ Numerous studies have indicated that GA plays an important role in suppressing tumorigenesis by inhibiting tumor growth and metastasis. ${ }^{8,12,39}$ However, little is known about the molecular mechanisms underlying the anticancer activity of this compound, especially in sarcoma. In the present study, we demonstrated that proliferation of human sarcoma cells is inhibited by GA in vitro and in vivo via G0/G1 arrest, autophagy, and apoptosis. In cells subjected to persistent and intense stimuli, autophagy exerts a protective effect to maintain normal survival; in the present work, autophagy was induced by ER stress via the IRE $1 a-J N K / c-j u n$ pathway. Furthermore, autophagy or JNK inhibition increased GAinduced apoptosis rate and cell death.

Apoptosis represents an important strategy for the eradication of tumor cells and treatment of cancer. Here, we reveal that GA induces apoptosis through both extrinsic and intrinsic pathways. Surprisingly, as cell death was not found to be entirely prevented by the caspase inhibitor, we examined other caspase-independent pathways. Huang et al. ${ }^{40}$ found that AIF plays an important role in GA-induced apoptosis in the absence of caspases. Furthermore, Endonuclease G (Endo $\mathrm{G})$, another apoptogenic protein present in the mitochondrial intermembrane space, translocates to the nucleus and directly cleaves nuclear DNA independent of caspase activity. ${ }^{41}$ Accordingly, we examined the expression of AIF or Endo G: no apparent difference in their expression was detected 
a

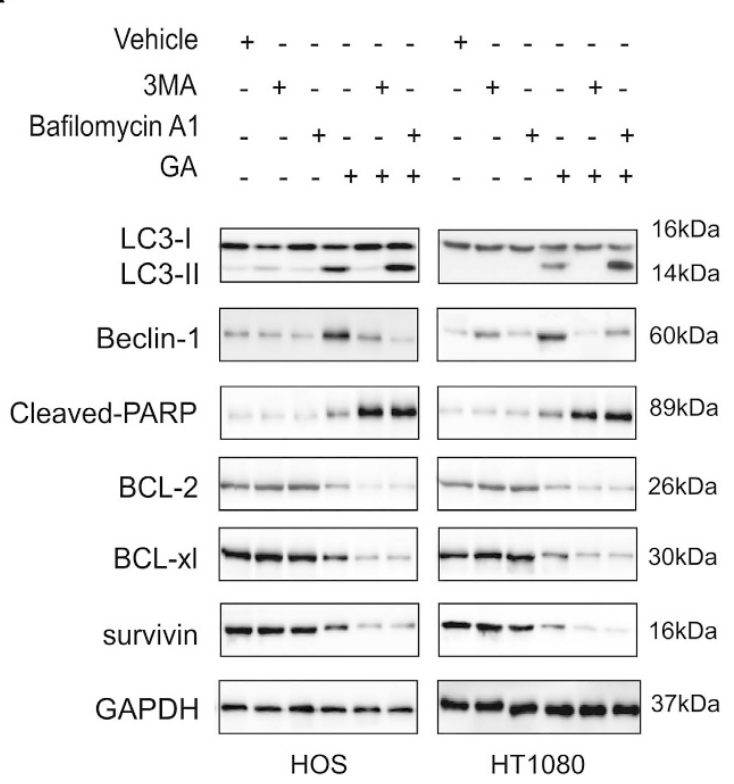

d
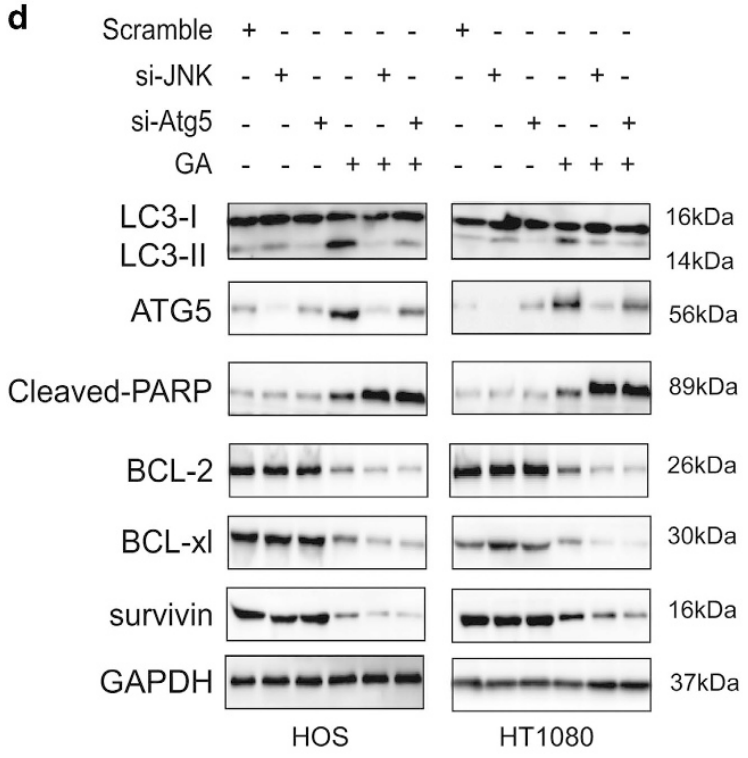

b

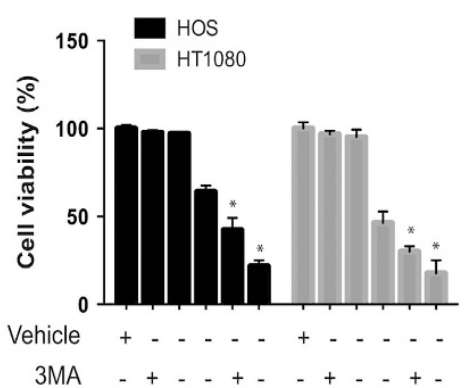

Bafilomycin A1

c

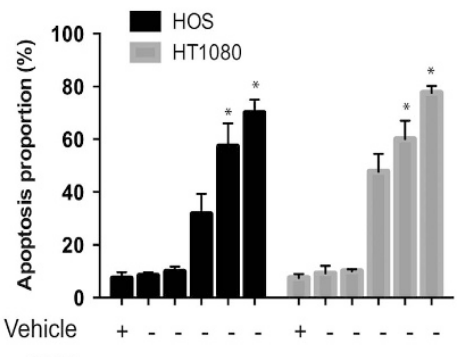

Bafilomycin A1

e

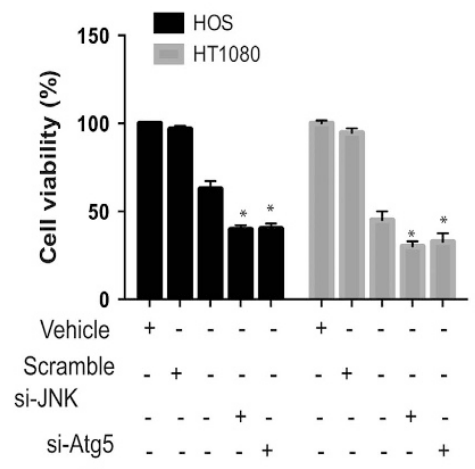

GA

f

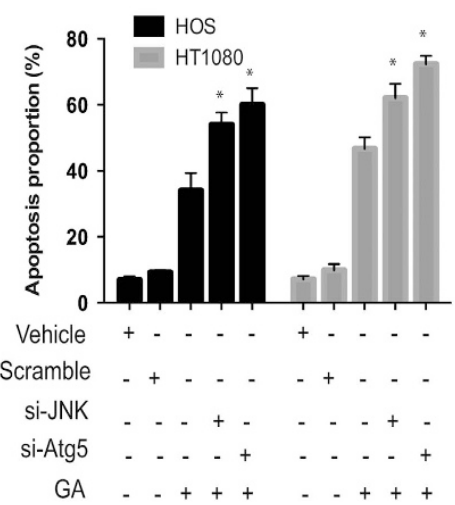

between the mitochondria and cytosol in GA-treated cells (data not shown).

Autophagy, which serves as another caspase-independent cell death pathway, was investigated. TEM revealed the accumulation of $\mathrm{AO}$ and MDC-staining acidic vesicles, upregulation of LC3B-II, and formation of autophagosomes, indicating the induction of autophagy following GA treatment. Furthermore, we investigated GA-induced autophagy and the 
Figure 7 Inhibition of autophagy or JNK enhances GA-induced cell proliferative inhibition and apoptosis in sarcoma cells. (a) 3-MA or bafilomycin A1 was pretreated to HOS and HT1080 cells for $6 \mathrm{~h}$ before incubating in GA $(40 \mu \mathrm{M})$ for $24 \mathrm{~h}$. Western blot analysis examined the protein expression level of Beclin-1, BCL-2, BCL-xl, survivin, cleavedPARP, and LC3 conversion. (b) After pretreatment with 3-MA or bafilomycin A1 for $6 \mathrm{~h}, \mathrm{HOS}$ and HT1080 cells were incubated in GA (40 $\mu$ M) for $24 \mathrm{~h}$. Then, MTT assay was used to test cell viability to calculate the growth index. (c) Cells in (b) were analyzed by flow cytometry. Histograms were shown for analyzed cells $(n=3)$. ${ }^{*} P<0.05$. (d) After knockdown of JNK or Atg5 by siRNA, HOS and HT1080 cells were incubated with $40 \mu \mathrm{M}$ of GA for $24 \mathrm{~h}$. Western blot analysis examined the protein expression level of Atg5, BCL-2, BCL-xl, survivin, cleaved-PARP, and LC3 conversion. (e) After knockdown of JNK or Atg5 by siRNA, HOS and HT1080 cells were incubated in GA (40 $\mu \mathrm{M}$ ) for $24 \mathrm{~h}$. Then, MTTassay was used to test cell viability to calculate the growth index. (f) Cells in (e) were analyzed by flow cytometry. Histograms were shown for analyzed cells $(n=3)$. ${ }^{*} P<0.05$

underlying mechanism. We found that treatment with GA induced a considerable increase in JNK and c-Jun phosphorylation. In addition, the expression of JNK was found to be correlated with that of IRE1. However, the data did not support the conclusion that the activation of the JNK pathway occurred before the induction of ER stress. ${ }^{42}$ Our study demonstrated that GA treatment led to remarkable increases in JNK phosphorylation in sarcoma cells that could, in turn, be reversed by treatment with the JNK inhibitor, SP600125, or with siRNA targeting IRE1. The results of current study show that JNK acts downstream of IRE1. Overall, our data suggest that GA induces autophagy in sarcoma cells, partly through stimulation of the ER stress response via activation of the IRE1/JNK pathway.

The effects of autophagy (prodeath or prosurvival) depend on the cell type involved and stimulator used. ${ }^{43}$ For example, in hepatocellular carcinoma, the anticancer effects of linifanib are enhanced by the inhibition of autophagy; however, in rhabdomyosarcoma, autophagy results in a decrease in the antitumor effects of piperlongumine. ${ }^{44}$ The cytotoxic effects of gefitinib against glioma cells mainly involve cell death through autophagy; however, in lung cancer cells, autophagy induced by gefitinib exerts a cytoprotective effect. ${ }^{45,46}$ Several studies have suggested that autophagy serves as a cell survival mechanism in GA-treated cancers. ${ }^{47,48}$ Consistent with these findings, the current study indicated that inhibition of JNK/c-jun pathway or GA-induced autophagy significantly increased apoptosis rates and cell death, suggesting GA- induced cytoprotective autophagy in sarcoma cells. However, IRE1a knockdown failed to elicit an increase in GA-induced cell apoptosis (Supplementary Figure S2) that may be attributed to the activation of both autophagy and apoptosis by IRE1a. However, the mechanism by which IRE1a activates GAinduced apoptosis remains to be determined.

ER stress response-mediated apoptosis and cell death are significantly prevented by the activation of autophagy, thus sustaining cell survival as well as homeostasis. One of the main reasons for the limited effects of chemotherapy drugs is the development of drug resistance. Previous studies have demonstrated that the activation of autophagy following ER stress during chemotherapy is related to the development of drug resistance in cancer. ${ }^{49}$ To our knowledge, no previous indepth findings related to the mechanisms of action of GA in other cancer cell types have been reported. Here, we showed that autophagy blockage greatly improves the cytotoxic effects of GA in sarcoma cells. Furthermore, the negative effects of autophagy on GA-induced apoptosis in sarcoma cancer cells were found to be abolished by autophagy inhibitors. The present findings suggest that the use of such inhibitors serves to enhance the therapeutic effects of GA and improve cancer prognosis.
In conclusion, the present study is the first to demonstrate that GA effectively inhibits the proliferation of sarcoma cells by causing G0/G1-phase arrest, and leads to cell death by inducing apoptosis. In the osteosarcoma xenograft model, GA was found to elicit significant antitumor activity with low levels of toxicity. Furthermore, in sarcoma cells, the IRE1 pathway appears to play a critical role in ER stress-activated autophagy following GA treatment; this counters ER stress-induced apoptosis and exerts protective effects against cell death. The blockage of autophagy or the JNK pathway enhances the antiproliferative effect of GA. Our results suggest that targeting the autophagy pathway in combination with GA treatment serves as a novel strategy for sarcoma therapy.

\section{Materials and Methods}

Cell culture. HOS human osteosarcoma cells (ATCC: CRL-1543) and HT1080 human fibrosarcoma cells (ATCC: CCL-121) were obtained from the American Type Culture Collection (ATCC, Manassas, VA, USA). The cells were cultured in Eagle's minimum essential medium (MEM) (Gibco BRL, Grand Island, NY, USA) supplemented with $10 \%(\mathrm{v} / \mathrm{v})$ fetal bovine serum (FBS) and $1 \%(\mathrm{v} / \mathrm{v})$ antibiotics (100 U/ml penicillin and $100 \mu \mathrm{g} / \mathrm{ml}$ streptomycin). The cells were maintained in an incubator set to $37^{\circ} \mathrm{C}$ with $5 \% \mathrm{CO}_{2}$.

Reagents and antibodies. GA was acquired from the National Institutes for Food and Drug Control in Shenzhen, Guangdong, China. The 3-(4,5-dimethylthiazol-2-yl)-2,5-diphenyltetrazolium bromide (MTT), SP600125, chloroquine (CQ), and DMSO were obtained from Sigma (St. Louis, MO, USA). MEM medium, FBS, penicillin, streptomycin, and phosphate-buffered saline (PBS) were purchased from Gibco Life Technologies (Grand Island, NY, USA). Hoechst 33342 was obtained from Molecular Probes (Grand Island, NY, USA). Primary antibodies, including cleaved-poly (ADP-ribose) polymerase (PARP), Beclin1, p62, LC3, p-JNK (Thr183/ Tyr185), JNK, p-c-jun (ser63), c-jun, IRE1 $\alpha$, together with GAPDH antibodies and secondary antibodies, were purchased from Cell Signaling Technology, Inc. (Beverly, MA, USA). 3MA were purchased from Selleckchem (Houston, TX, USA). Antibodies against caspase-3, -8 , and $-9, \mathrm{Bcl}-2, \mathrm{Bcl}-\mathrm{xl}$, survivin, Cyclin D1, Cyclin E, and Cdk4 were purchased from Abcam (Cambridge, England).

MTT assay. MTT assay was employed to examine the effects of GA on the proliferation of sarcoma cells. Briefly, the cells were seeded in 96-well plates at $2 \times 10^{3}$ cells/well in $200 \mu \mathrm{l}$ medium. Then, the cells in the wells were treated with various concentrations of GA and cultured for 24,48 , or $72 \mathrm{~h}$. At the end of culture, MTT solution $(0.5 \mathrm{mg} / \mathrm{ml}$ in $20 \mu$ PBS) was added to each well and incubated for $4 \mathrm{~h}$ at $37^{\circ} \mathrm{C}$. An Erlotinib mesylate enzyme-labeled instrument (Thermo, Waltham, MA, USA) was used to measure the absorbance of each well at $570 \mathrm{~nm}$. Data were calculated from three independent experiments, each performed in sextuplicate.

Detection of acidic vesicular organelles. Formation of acidic vesicular organelles (AVOs), a morphological characteristic of autophagy, was detected by acridine orange $(A O)$ staining. Cells were stained with $1 \mu \mathrm{g} / \mathrm{ml}$ acridine orange for $20 \mathrm{~min}$ and the samples were observed under a laser scanning confocal microscopy (excitation, $546 \mathrm{~nm}$; emission, 575/640 nm).

Visualization of autophagic vacuoles. The autofluorescent agent MDC was used as a specific autophagolysosome marker to analyze the autophagic process. Sarcoma cells were treated with different concentrations of GA for $24 \mathrm{~h}$. Autophagic vacuoles were labeled with MDC by incubating cells with $50 \mu \mathrm{M} M D C$ in 

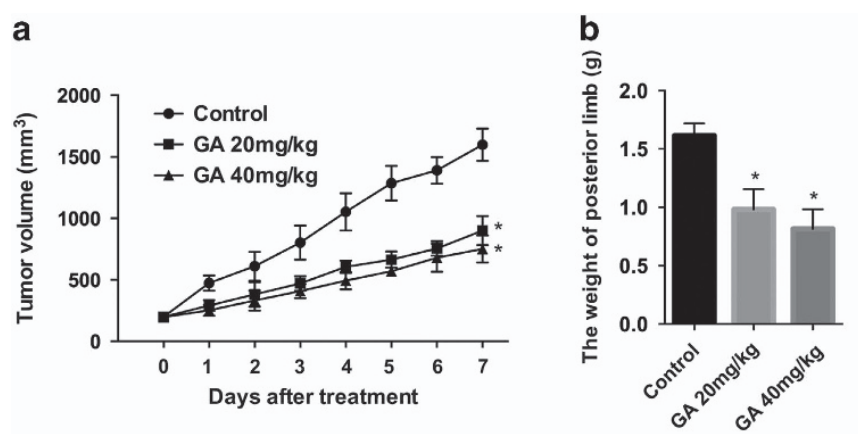

c

d
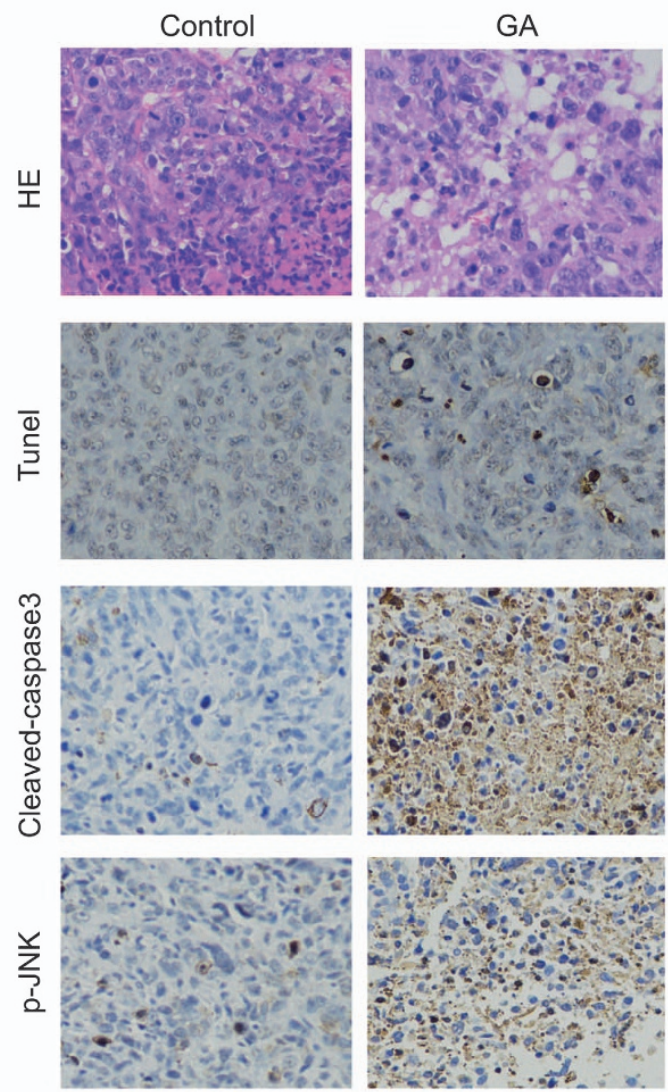

e

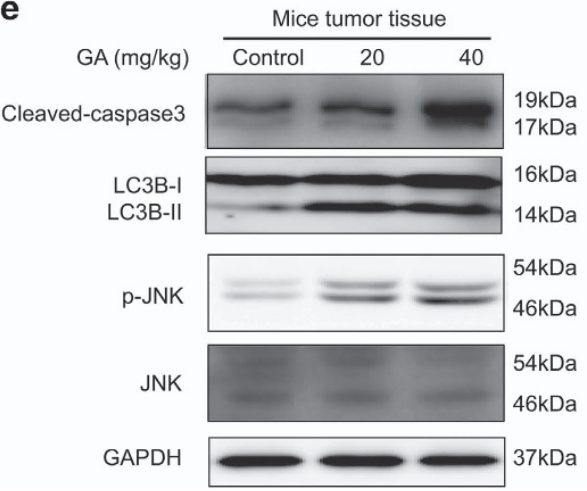

$f$
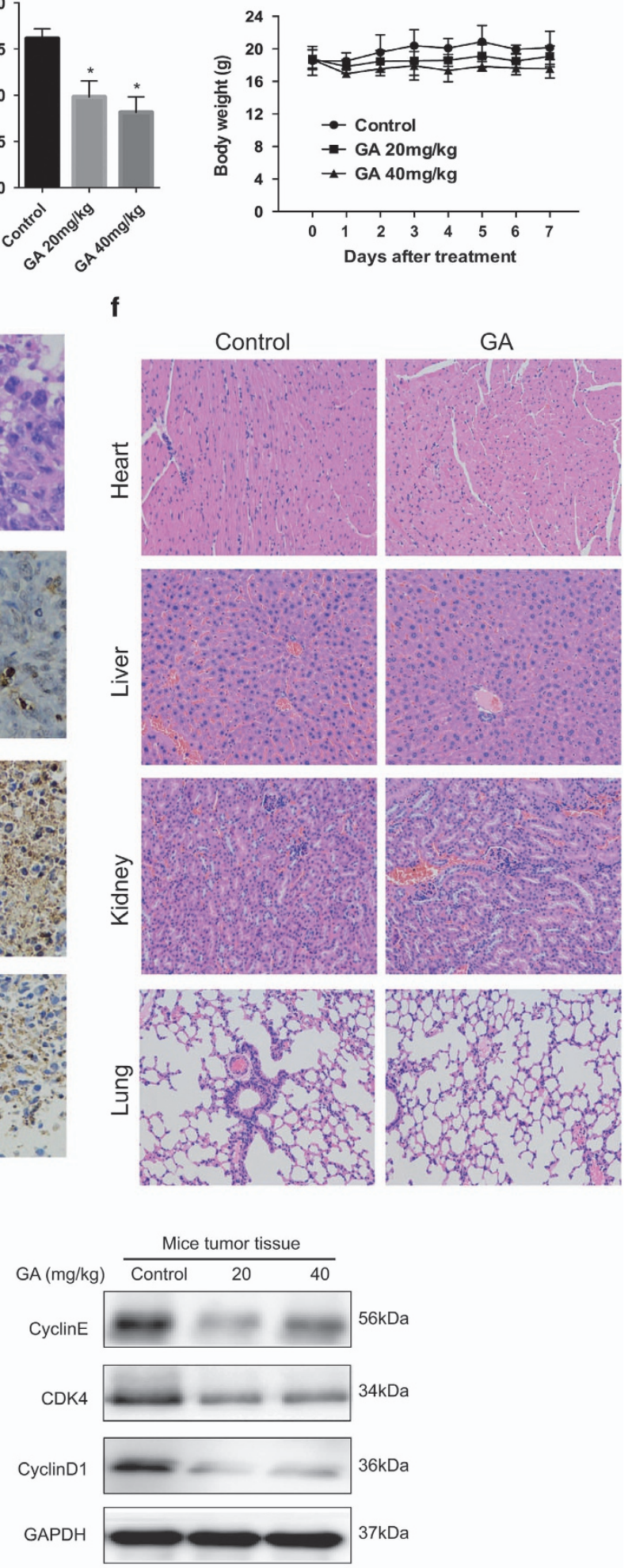
Figure 8 GA inhibits OS xenograft growth in vivo. HOS cells were orthotopically inoculated into the left tibia of BALB/c-nu mice. At 1 week after tumor inoculation, mice were randomly divided into two groups for treatment. Intraperitoneal administration of vehicle or GA (20 or $40 \mathrm{mg} / \mathrm{kg}$ ) every other day for seven times. (a) Tumor volume was measured every week. (b) GA treatment resulted in significantly lower than control group. (c) Body weights were measured every week. (d) The apoptotic status of tumor tissues was assessed by TUNEL assay. H\&E staining was used to evaluate the histology. The expression levels of cleaved caspase-3 and phospho-JNK were also examined by immunohistochemistry. Representative images were presented. Bar, $50 \mu \mathrm{m}$. (e) The levels of cleaved caspase-3, LC3-I/II, phospho-JNK, total JNK, Cyclin E, CDK4, and Cyclin D1 in tumor xenograft tissues were measured by western blot. (f) No major organ-related toxicities was observed. H\&E staining was used to evaluate the histology

PBS at $37^{\circ} \mathrm{C}$ for $20 \mathrm{~min}$. After incubation, cells were washed three times with PBS and immediately analyzed by a laser scanning confocal microscopy (excitation, $390 \mathrm{~nm}$; emission, $460 \mathrm{~nm}$ ).

Colony-formation assay. Cells were seeded in six-well plates at a density of 1000 cells per well. In the drug treatment group, the medium was changed with fresh medium containing GA $(10-40 \mu \mathrm{M})$ for $\sim 14$ days until the cells grew to visible colonies. Colonies were fixed with $4 \%$ paraformaldehyde and stained by crystal violet for $15 \mathrm{~min}$ at room temperature. The colonies that consisted of 450 cells were counted.

Transwell migration assay. Transwell assay was conducted as described previously with some modifications. Serum-free medium was added to the top chamber of 24-well transwell plate (Millipore, Plano, TX, USA), and the bottom chambers were filled with $600 \mu \mathrm{l}$ DMEM medium containing various growth factors. The top chambers were seeded with $100 \mu \mathrm{l}$ DMEM medium and sarcoma cells $\left(4 \times 10^{4}\right.$ cells per well). Immediately, $100 \mu$ l DMEM medium with various concentrations of GA was added to the upper chamber. After $24 \mathrm{~h}$, migrated cells were fixed in $4 \%$ paraformaldehyde and stained with $0.05 \%$ crystal violet. Images were taken using a ZEISS (Heidenheim, Germany) digital microscope and invading cells were counted by manual counting. The assays were replicated three times.

Cell cycle analysis by flow cytometry. Cells were seeded in six-well plates with a density of $1 \times 10^{6} / \mathrm{ml}$ and then treated with GA at different concentrations for $24 \mathrm{~h}$. After GA treatment, the cells were harvested, washed with PBS, and fixed with cold $75 \%$ ethyl alcohol at $4{ }^{\circ} \mathrm{C}$ overnight. The cells were then again washed with PBS and incubated with RNase $\mathrm{A}$ for 30 min followed by staining with $500 \mu \mathrm{l}$ propidium iodide for $30 \mathrm{~min}$ at room temperature. Cell cycle analysis was performed on the Accuri C6 (BD Biosciences, Mountain View, CA, USA).

Morphological apoptosis. Cells were cultured at a density of $1 \times 10^{5} / \mathrm{ml}$ per well on coverslips in 6-well plates and then treated with 10-40 $\mu \mathrm{M}$ GA for $24 \mathrm{~h}$. After incubation, cells were washed twice with PBS, fixed with $4 \%$ paraformaldehyde for $30 \mathrm{~min}$, and then stained with Hoechst 33342 solution $(5 \mu \mathrm{g} / \mathrm{ml})$ for $10 \mathrm{~min}$ in the dark at $37^{\circ} \mathrm{C}$. Cells were assessed by fluorescence microscope for morphological changes of the nucleus.

Mitochondrial membrane potential assay. The JC-1 Assay Kit (Beyotime, Beijing, China) was used to measure the alteration of mitochondrial membrane potential according to the manufacturer's instructions. Cells were seeded in 6-well plates with a density of $5 \times 10^{5} / \mathrm{ml}$ and then treated with GA at concentrations ranging from 10 to $40 \mu \mathrm{M}$ for $24 \mathrm{~h}$. Then, $100 \mu \mathrm{l}$ of JC- 1 staining solution was added into $1 \mathrm{ml}$ of culture medium and incubated for $20 \mathrm{~min}$ at $37^{\circ} \mathrm{C}$ in a $\mathrm{CO}_{2}$ incubator. The samples were analyzed by flow cytometry, and JC-1 aggregate was measured at the FL-2 channel and green fluorescent (both JC-1 monome) at the FL-1 channel (BD Biosciences).

Apoptosis analysis by flow cytometry. Cells were seeded in 6-well plates with a density of $1 \times 10^{6} / \mathrm{ml}$ and then treated with GA at concentrations ranging from 0 to $40 \mu \mathrm{M}$ for $24 \mathrm{~h}$. After GA treatment, cells were harvested, washed twice with cold PBS, and resuspended in the $1 \times$ binding buffer. Then, cells were incubated with FITCconjugated annexin $\mathrm{V}$ and $\mathrm{PI}$ for $15 \mathrm{~min}$ in the dark at room temperature, and the samples were analyzed using the flow cytometry in $1 \mathrm{~h}$ (BD Biosciences).

Western blotting analysis. Cells were cultured in 6-well plates at a density of $5 \times 10^{5} / \mathrm{ml}$ per well and then treated with GA $(0-40 \mu \mathrm{M})$ for $24 \mathrm{~h}$. Cells were washed with PBS and lysed in ice-cold RIPA containing a protease and a phosphatase inhibitor cocktail for $30 \mathrm{~min}$ on ice. Cell lysates were centrifuged at $13000 \times \mathrm{g}$ for $15 \mathrm{~min}$ at $4^{\circ} \mathrm{C}$, and the supernatant was collected. Protein concentrations were quantified using the BSA Protein Assay (Thermo) according to the manufacturer's instructions. Equal amounts $(30 \mu \mathrm{g})$ of total protein were separated by SDS-PAGE (8-12\%) at $100 \mathrm{~V}$ for $1.5 \mathrm{~h}$ and transferred to $0.45 \mu \mathrm{m}$ PVDF membrane at $100 \mathrm{~V}$ for $1 \mathrm{~h}$. After blocking with $5 \%$ nonfat milk in PBST buffer for $1 \mathrm{~h}$ at room temperature, the membranes were incubated with primary antibody at $4{ }^{\circ} \mathrm{C}$ overnight. The membranes were washed three times with PBST buffer and then incubated with peroxidase-conjugated secondary antibody for $1 \mathrm{~h}$ at room temperature. Specific antibody binding was detected by the Chemiluminescence Kit (Millipore)

\section{Orthotopic xenograft}

OS mouse model: Female BALB/c-nu mice (Shanghai Slac Laboratory Animal Co., Ltd, Shanghai, China) were purchased at 4 weeks of age and housed in a standard animal laboratory with free access to water and food. HOS cells were digested and washed by cold PBS for three times, and the final concentration was $1 \times 10^{7} / \mathrm{ml}$ in cold PBS. A volume of $100 \mu \mathrm{l}$ cell suspension was injected into medullary cavity of tibia. When the tumors in the tibia were macroscopic, mice were randomly divided into three groups: control group and two GA group (six mice in each group). Control group received intraperitoneal injection of $100 \mu \mathrm{l} 5 \%$ DMSO every other day, whereas GA group was injected with $100 \mu \mathrm{l} \mathrm{GA}$ (20 or $40 \mathrm{mg} / \mathrm{kg}$, diluted with $5 \%$ DMSO). After seven times of drug administration, the mice were killed, and the tumors were removed, weighted, and fixed for use in immunohistochemical experiments. All the animal-related procedures were approved by the animal care and use committee of Sir Run Run Shaw Hospital.

TUNEL assay. Apoptosis detection was identified using a TUNEL Assay Kit (Beyotime) according to the manufacturer's instructions. In brief, paraffin-embedded slides were deparaffinized with xylene and ethanol and rehydrated cell by proteinase $\mathrm{K}$. After several washes with PBS, sections were incubated with TUNEL reaction mixture freshly prepared for $1 \mathrm{~h}$ at $37^{\circ} \mathrm{C}$ in a moist chamber. Apoptotic cells on the slides were observed under an Olympus light microscope (Olympus, Tokyo, Japan) in randomly chosen fields.

Histopathology and immunohistochemistry. Formalin-fixed tissue samples were embedded in paraffin and $4 \mu \mathrm{m}$ sections were cut. Primary tumors, heart, liver, spleen, lung, and kidney sections were stained with H\&E for routine histological examinations and morphometric analysis. For immunohistochemical staining, slides were deparaffinized in xylene and rehydrated with graded alcohol and incubated in $3 \%$ hydrogen peroxide to block the endogenous peroxidase activity. Antigen retrieval was performed by boiling the slides in $10 \mathrm{mM}$ sodium citrate ( $\mathrm{pH}$ 6.0) for $30 \mathrm{~min}$. Then, slides were blocked in 10\% normal goat serum for $15 \mathrm{~min}$, followed by incubation with p-JNK, and cleaved caspase- 3 at $4{ }^{\circ} \mathrm{C}$ overnight in a moist chamber. On the next day, slides were washed in PBS and incubated with the second antibody for $1 \mathrm{~h}$ at room temperature. Immunoreactivity was detected using the Vectastain Elite DAB KIT (Vector Laboratories, Burlingame, CA, USA).

Statistical analysis. Statistical analysis was performed using the SPSS version 18.0 software (IBM Corporation, Chicago, IL, USA). Student's t-test, Fisher's exact test, and one-way ANOVA were used for calculating the significance between different groups. Statistical significance is indicated by $P<0.05$. All data were expressed as mean \pm S.D. of three independent experiments.

\section{Conflict of Interest}

The authors declare no conflict of interest.

Acknowledgements. The study was sponsored by the National Nature Science Fund of China (81472064 and 81601925), Medical Science and Technology Project of Zhejiang Province (2017179447). 


\section{Publisher's Note}

Springer Nature remains neutral with regard to jurisdictional claims in published maps and institutional affiliations.

1. Skubitz KM, D'Adamo DR. Sarcoma. Mayo Clin Proc 2007; 82: 1409-1432.

2. Soo KY, Atkin JD. Autophagy dysregulation by mutant fused in sarcoma-implications for amyotrophic lateral sclerosis. Cell Death Dis 2015; 6: e1945

3. Ma L, Maruwge W, Strambi A, D'Arcy P, Pellegrini P, Kis L et al. SIRT1 and SIRT2 inhibition impairs pediatric soft tissue sarcoma growth. Cell Death Dis 2014; 5: e1483.

4. Longhi A, Errani $C$, De Paolis M, Mercuri M, Bacci G. Primary bone osteosarcoma in the pediatric age: state of the art. Cancer Treat Rev 2006; 32: 423-436.

5. Marina N, Gebhardt M, Teot L, Gorlick R. Biology and therapeutic advances for pediatric osteosarcoma. Oncologist 2004; 9: 422-441.

6. Bielack SS, Carrle D. State-of-the-art approach in selective curable tumors: bone sarcoma Ann Oncol 2008; 19: vii155-vii160.

7. Cao DH, Jiang J, You LL, Jia ZF, Tsukamoto T, Cai HK et al. The protective effects of $18 \beta$ glycyrrhetinic acid on Helicobacter pylori-infected gastric mucosa in Mongolian Gerbils. Biomed Res Int 2016; 2016: 4943793.

8. Wang XF, Zhou QM, Lu YY, Zhang H, Huang S, Su SB. Glycyrrhetinic acid potently suppresses breast cancer invasion and metastasis by impairing the p38 MAPK-AP1 signaling axis. Expert Opin Ther Targets 2015; 19: 577-587.

9. Kong SZ, Chen HM, Yu XT, Zhang X, Feng XX, Kang XH et al. The protective effect of 18beta-Glycyrrhetinic acid against UV irradiation induced photoaging in mice. Exp Gerontol 2015; 61: 147-155.

10. Zhu LC, Yang X, Tan J, Wang BC, Zhang X. A validated high performance liquid chromatograph-photodiode array method for simultaneous determination of 10 bioactive components in compound Hongdoushan capsule. Pharmacogn Mag 2014; 10: 83-88.

11. Tang ZH, Zhang LL, Li T, Lu JH, Ma DL, Leung $\mathrm{CH}$ et al. Glycyrrhetinic acid induces cytoprotective autophagy via the inositol-requiring enzyme 1alpha-c-Jun $\mathrm{N}$-terminal kinase cascade in non-small cell lung cancer cells. Oncotarget 2015; 6: 43911-43926.

12. Lin DJ, Zhong W, Li J, Zhang B, Song G, Hu TH. Involvement of BID translocation in glycyrrhetinic acid and 11-deoxy glycyrrhetinic acid-induced attenuation of gastric cancer growth. Nutr Cancer 2014;; 66: 463-473.

13. Wu CH, Chen AZ, Yen GC. Protective effects of glycyrrhizic acid and 18beta-glycyrrhetinic acid against cisplatin-induced nephrotoxicity in BALB/c mice. J Agric Food Chem 2015; 63: 1200-1209.

14. Kroemer G, Galluzzi L, Vandenabeele P, Abrams J, Alnemri ES, Baehrecke EH et al. Classification of cell death: recommendations of the Nomenclature Committee on Cell Death 2009. Cell Death Differ 2009; 16: 3-11.

15. Zimmermann KC, Bonzon C, Green DR. The machinery of programmed cell death. Pharmacol Ther 2001; 92: 57-70.

16. de Bruin EC, Medema JP. Apoptosis and non-apoptotic deaths in cancer development and treatment response. Cancer Treat Rev 2008; 34: 737-749.

17. Eisenberg-Lerner A, Bialik S, Simon HU, Kimchi A. Life and death partners: apoptosis, autophagy and the cross-talk between them. Cell Death Differ 2009; 16: 966-975.

18. Heras-Sandoval D, Perez-Rojas JM, Hernandez-Damian J, Pedraza-Chaverri J. The role of PI3K/AKT/mTOR pathway in the modulation of autophagy and the clearance of protein aggregates in neurodegeneration. Cell Signal 2014; 26: 2694-2701.

19. Tanemura M, Ohmura Y, Deguchi T, Machida T, Tsukamoto R, Wada H et al. Rapamycin causes upregulation of autophagy and impairs islets function both in vitro and in vivo. $\mathrm{Am} \mathrm{J}$ Transplant 2012; 12: 102-114.

20. Rangaraju S, Verrier JD, Madorsky I, Nicks J, Dunn WAJ, Notterpek L. Rapamycin activates autophagy and improves myelination in explant cultures from neuropathic mice. $J$ Neurosc 2010; 30: 11388-11397.

21. Moruno-Manchon JF, Perez-Jimenez E, Knecht E. Glucose induces autophagy under starvation conditions by a p38 MAPK-dependent pathway. Biochem J 2013; 449: 497-506.

22. Tang ZH, Li T, Chang LL, Zhu H, Tong YG, Chen XP et al. Glycyrrhetinic acid triggers a protective autophagy by activation of extracellular regulated protein kinases in hepatocellular carcinoma cells. J Agric Food Chem 2014; 62: 11910-11916.

23. Li T, Tang ZH, Xu WS, Wu GS, Wang YF, Chang LL et al. Platycodin D triggers autophagy through activation of extracellular signal-regulated kinase in hepatocellular carcinoma HepG2 cells. Eur J Pharmacol 2015; 749: 81-88.

24. Hayashi-Nishino M, Fujita N, Noda T, Yamaguchi A, Yoshimori T, Yamamoto A. A subdomain of the endoplasmic reticulum forms a cradle for autophagosome formation. Nat Cell Biol 2009; 11: 1433-1437.

25. Yla-Anttila P, Vihinen H, Jokitalo E, Eskelinen EL. 3D tomography reveals connections between the phagophore and endoplasmic reticulum. Autophagy 2009; 5: 1180-1185.

26. Raciti M, Lotti LV, Valia S, Pulcinelli FM, DiRenzo L. JNK2 is activated during ER stress and promotes cell survival. Cell Death Dis 2012; 3: e429.

27. Fuest M, Willim K, MacNelly S, Fellner N, Resch GP, Blum HE et al. The transcription factor $\mathrm{C}$-Jun protects against sustained hepatic endoplasmic reticulum stress thereby promoting hepatocyte survival. Hepatology 2012; 55: 408-418.

28. Adams JM. Ways of dying: multiple pathways to apoptosis. Genes Dev2003; 17: 2481-2495.
29. Xu L, Fan Q, Wang X, Zhao X, Wang L. Inhibition of autophagy increased AGE/ROSmediated apoptosis in mesangial cells. Cell Death Dis 2016; 7: e2445.

30. Li DD, Wang LL, Deng R, Tang J, Shen Y, Guo JF et al. The pivotal role of c-Jun NH2terminal kinase-mediated Beclin 1 expression during anticancer agents-induced autophagy in cancer cells. Oncogene 2009; 28: 886-898.

31. Siddiqui MA, Malathi $K$. RNase L induces autophagy via c-Jun N-terminal kinase and doublestranded RNA- dependent protein kinase signaling pathways. J Biol Chem 2012; 287: 43651-43664.

32. Bennett BL, Sasaki DT, Murray BW, O'Leary EC, Sakata ST, Xu W et al. SP600125, an anthrapyrazolone inhibitor of Jun N-terminal kinase. Proc Natl Acad Sci USA 2001; 98: 13681-13686.

33. Raciti M, Lotti LV, Valia S, Pulcinelli FM, DiRenzo L. JNK2 is activated during ER stress and promotes cell survival. Cell Death Dis 2012; 3: e4.

34. Ichimura Y, Kumanomidou T, Sou YS, Mizushima T, Ezaki J, Ueno T et al. Structural basis for sorting mechanism of p62 in selective autophagy. J Biol Chem 2008; 283: 22847-22857.

35. Yang ZJ, Deng CM, Qiu YH. Clinical efficacy of Baihegujin decoction combined with chemotherapy in treating 32 patients with advanced lung cancer. Hebei J TCM 2002; 24: 166-188.

36. Zhou B, Shan ZS, Fang MM, Chen YC, Wu XY, Xiao LD. Clinical observation on modified Liujunzi decoction in combination with chemotherapy in treatment of 31 advanced non-small cell lung cancer patients. J Tradit Chin Med 2015; 56: 219-222.

37. Kawakami J, Yamamura Y, Santa T, Kotaki H, Uchino K, Sawada Y et al. Kinetic analysis of glycyrrhetic acid, an active metabolite of glycyrrhizin, in rats: role of enterohepatic circulation. J Pharm Sci 1993; 82: 301-305.

38. Yamamura Y, Kawakami J, Santa T, Kotaki H, Uchino K, Sawada Y et al. Pharmacokinetic profile of glycyrrhizin in healthy volunteers by a new high-performance liquid chromatographic method. J Pharm Sci 1992; 81: 1042-1046.

39. Wang ZY, Agarwal R, Zhou ZC, Bickers DR, Mukhtar H. Inhibition of mutagenicity in Salmonella typhimurium and skin tumor initiating and tumor promoting activities in SENCAR mice by glycyrrhetinic acid: comparison of 18 alpha- and 18 beta-stereoisomers. Carcinogenesis 1991; 12: 187-192.

40. Huang YC, Kuo CL, Lu KW, Lin JJ, Yang JL, Wu RS et al. 18 $\alpha$-glycyrrhetinic acid induces apoptosis of $\mathrm{HL}-60$ human leukemia cells through caspases- and mitochondria-dependent signaling pathways. Molecules 2016; 21: E872.

41. Lin H, Liu XY, Subramanian B, Nakeff A, Valeriote F, Chen BD. Mitotic arrest induced by XK469, a novel antitumor agent, is correlated with the inhibition of cyclin B1 ubiquitination. Int J Cancer 2002; 97: 121-128.

42. Win S, Than TA, Fernandez-Checa JC, Kaplowitz N. JNK interaction with Sab mediates ER stress induced inhibition of mitochondrial respiration and cell death. Cell Death Dis 2014; 5: e989.

43. Gump JM, Staskiewicz L, Morgan MJ, Bamberg A, Riches DW, Thorburn A. Autophagy variation within a cell population determines cell fate through selective degradation of Fap-1. Nat Cell Biol 2014; 16: 47-54.

44. Wang $Y$, Wang JW, Xiao X, Shan $Y$, Xue B, Jiang G et al. Piperlongumine induces autophagy by targeting p38 signaling. Cell Death Dis 2013; 3: e824.

45. Chang CY, Kuan YH, Ou YC, Li JR, Wu CC, Pan PH et al. Autophagy contributes to gefitinibinduced glioma cell growth inhibition. Exp Cell Res 2014; 327: 102-112.

46. Han WD, Pan HM, Chen Y, Sun J, Wang YS, Li J et al. EGFR tyrosine kinase inhibitors activate autophagy as a cytoprotective response in human lung cancer cells. PLOS ONE 2011; 6: e18691.

47. Tang ZH, Li T, Chang LL, Zhu H, Tong YG, Chen XP et al. Glycyrrhetinic acid triggers a protective autophagy by activation of extracellular regulated protein kinases in hepatocellular carcinoma cells. J Agric Food Chem 2014; 62: 11910-11916.

48. Cao D, Jiang J, You L, Jia Z, Tsukamoto T, Cai $\mathrm{H}$ et al. The protective effects of $18 \beta$ glycyrrhetinic acid on Helicobacter pylori-infected gastric mucosa in Mongolian Gerbils. Biomed Res Int 2016; 2016: 4943793.

49. Ren JH, He WS, Nong L, Zhu QY, Hu K, Zhang RG et al. Acquired cisplatin resistance in human lung adenocarcinoma cells is associated with enhanced autophagy. Cancer Biother Radiopharm 2010; 25: 75-80.

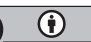

Cell Death and Disease is an open-access journal published by Nature Publishing Group. This work is licensed under a Creative Commons Attribution 4.0 International License. The images or other third party material in this article are included in the article's Creative Commons license, unless indicated otherwise in the credit line; if the material is not included under the Creative Commons license, users will need to obtain permission from the license holder to reproduce the material. To view a copy of this license, visit http://creativecommons.org/licenses/by/4.0/

(C) The Author(s) 2017 